\title{
Integration of Fuzzy Matter-Element Method and 3D-QSAR Model for Generation of Environmentally Friendly Quinolone Derivatives
}

\author{
Xixi Li, Baiyu Zhang *(D), Wendy Huang, Cuirin Cantwell and Bing Chen \\ Northern Region Persistent Organic Pollution Control (NRPOP) Laboratory, Civil Engineering, Faculty of \\ Engineering and Applied Science, Memorial University, St. John's, NL A1B 3X5, Canada; x17724@mun.ca (X.L.); \\ wendyh@mun.ca (W.H.); cdcantwell@mun.ca (C.C.); bchen@mun.ca (B.C.) \\ * Correspondence: bzhang@mun.ca
}

Received: 19 March 2020; Accepted: 30 April 2020; Published: 6 May 2020

\begin{abstract}
The environmental pollution of quinolone antibiotics (QAs) has caused rising public concern due to their widespread usage. In this study, Gaussian 09 software was used to obtain the infrared spectral intensity (IRI) and ultraviolet spectral intensity (UVI) of 24 QAs based on the Density Functional Theory (DFT). Rather than using two single-factor inputs, a fuzzy matter-element method was selected to calculate the combined effects of infrared and ultraviolet spectra (CI). The Comparative Molecular Field Analysis (CoMFA) was then used to construct a three-dimensional quantitative structure-activity relationship (3D-QSAR) with QAs' molecular structure as the independent variable and $\mathrm{CI}$ as the dependent variable. Using marbofloxacin and levofloxacin as target molecules, the molecular design of $87 \mathrm{QA}$ derivatives was carried out. The developed models were further used to determine the stability, functionality (genetic toxicity), and the environmental effects (bioaccumulation, biodegradability) of these designed QA derivatives. Results indicated that all QA derivatives are stable in the environment with their IRI, UVI, and CI enhanced. Meanwhile, the genetic toxicity of the 87 QA derivatives increased by varying degrees $(0.24 \%-29.01 \%)$, among which the bioaccumulation and biodegradability of 43 QA derivatives were within the acceptable range. Through integration of fuzzy matter-element method and 3D-QSAR, this study advanced the QAs research with the enhanced $\mathrm{CI}$ and helped to generate the proposed environmentally friendly quinolone derivatives so as to aid the management of this class of antibiotics.
\end{abstract}

Keywords: quinolone antibiotics; infrared characteristic vibration spectrum; ultraviolet absorption spectrum; fuzzy matter-element method; three-dimensional quantitative structure-activity relationship; molecular modification

\section{Introduction}

Quinolone antibiotics (QAs) are a new class of artificially synthesized anti-infective drugs. They are widely used in the treatment of various infectious diseases due to their broad bactericidal spectrum, strong antibacterial properties, low toxicity, few side effects, and low price [1]. They are a class of antibiotics widely applied in veterinary medicine. After usage, QAs will remain in the animal as their original molecular structures or pass through feces and urine in the form of metabolites. These QAs and their metabolites will excrete into the external environment [2]. According to Xander et al. [3], 47 research papers have reported the distribution of QAs in the environment and found that their residues are concentrated worldwide including in Pearl River, Huangpu River, Xiaoqing River, Hai River, Baiyangdian Lake, and Dongting Lake in China; densely populated watersheds such as Lake Ontario in North America, Taft River and in Europe, and Mekong River in Asia. Zhang et al. [4] used the III 
fugacity model to study the distribution characteristics of QAs in 58 watersheds in China. The results showed that after metabolism in humans and animals, the total amount of QAs excreted from feces and urine is $5.4 \times 10^{7} \mathrm{~kg}$. Only $0.02 \times 10^{7} \mathrm{~kg}$ are removed in wastewater treatment, while the remaining $5.38 \times 10^{7} \mathrm{~kg}$ still directly enter the receiving environment. Chen et al. [5] used gas chromatography and mass spectrometry to detect QA concentrations in 19 key groundwater monitoring wells in Beijing. The average concentrations of the QAs ciprofloxacin and norfloxacin were found to be 4.9 and $0.2 \mathrm{ng}$, respectively. In addition, studies have shown that the levels of norfloxacin, ciprofloxacin, and enoxacin in groundwater in Spain, were 64.13, 38.93, $44.47 \mathrm{ng}$, respectively [6]. Norfloxacin, ciprofloxacin, and enoxacin in the groundwater of a Swedish pharmaceutical company reached 31, 14,000, and $1900 \mathrm{ng}$, respectively [7]. These studies have shown that the high residual concentrations of QAs are a threat to the environment. QAs accumulate in various aquatic organisms, however, the concentration of different QAs are quite different. QAs, including ofloxacin $(2.72 \mu \mathrm{g} / \mathrm{kg})$, enrofloxacin $(762.34 \mu \mathrm{g} / \mathrm{kg})$, and ciprofloxacin $(3.08 \mu \mathrm{g} / \mathrm{kg}$ ) were found in bivalve samples [8]. A mean value of ofloxacin (5.58 $\mu \mathrm{g} / \mathrm{kg})$, enrofloxacin $(3.08 \mu \mathrm{g} / \mathrm{kg})$, ciprofloxacin $(4.17 \mu \mathrm{g} / \mathrm{kg})$, and norfloxacin $(23.8 \mu \mathrm{g} / \mathrm{kg})$ were found in the muscles of fish, turtles, and birds from Baiyangdian Lake, China [9]. Li et al. [10] found that among 22 antibiotics, QAs had the highest concentration in 190 mollusks samples with a mean concentration of $86.76 \mu \mathrm{g} / \mathrm{kg}$ dry weight. The investigation of antibiotics in mollusks from Bohai Sea, China, indicated that the mean concentrations of QAs in the mollusks were in the order of "NOR $>$ OFL $>$ CIP $>$ FLE $>$ SAR $>$ LOM $>$ ENR > DIF". The bioaccumulation capacity of QAs is highly relevant to their molecular structures [10]. Therefore, it is of critical importance that the relationship between QAs molecular structures and their characteristics can be identified, so that environmentally friendly QA derivatives can be generated.

3D quantitative structure-activity relationship (3D-QSAR) models have been utilized to design and develop potent drugs by correlating 3D-structural features of the chemicals with properties of interest [11]. Among the existing 3D-QSAR methods, the Comparative Molecular Field Analysis (CoMFA) and the Comparative Molecular Similarity Indices Analysis (CoMSIA) are extensively used in the current practice of rational drug design [12]. 3D-QSAR has been applied to design environmentally friendly molecules. Wang et al. [13] designed a pentachlorophenol molecule with lower bioaccumulation by 3D-QSAR. Tong et al. [14] studied the design of HIV protease inhibitors by using a certain 3D-QSAR method (CoMFA or CoMSIA). Gu et al. [15] predicted the octanol-water partition coefficient for polychlorinated naphthalenes through 3D-QSAR models. However, there are still very limited studies about the use of 3D-QSAR to predict the environmentally friendly properties of QAs. Zhao et al. [16] combined QSAR/QSPR with molecular docking to examine the biodegradability of C20-carbonyl and the C21-carboxyl groups of fluoroquinolones. Zhao et al. [17] designed new fluoroquinolones using SYBYL-X 2.0. After changing the molecular groups, the photodegradability of new fluoroquinolones increased from $15.04 \%$ to $40.92 \%$ [17].

To construct a 3D-QSAR model for QA analysis, effective methods for detection of QAs in environmental samples are needed so as to obtain infrared and ultraviolet spectral characteristics of QAs to build the database. Infrared and ultraviolet spectral based analytical methods have been well developed for QA detection. Claine [18], Efthimiadou et al. [19], Skyrianou et al. [20], and Zampakou et al. [21] conducted infrared spectroscopy analysis to detect QAs. Bailac et al. [22] detected quinolones in chicken tissues by liquid chromatography based on ultraviolet spectral analysis. Zampakou et al. [21] studied the interaction of quinolone antimicrobial complexes with calf-thymus deoxyribonucleic acid investigated by ultraviolet spectroscopy. However, 3D-QSAR model development needs a large amount of infrared and ultraviolet spectral characteristics of QAs as inputs. Obtaining such information is expensive and time-consuming. Rather than using experimental analysis to generate infrared and ultraviolet spectral data, theoretical calculation methods [23,24] can assist QAs quantification to speed up the database generation. Among them, the Density Functional Theory (DFT) based calculation has been widely adopted. Qiu [25] et al. used DFT to calculate the infrared and ultraviolet spectra of phthalate esters and their derivatives, and used 3D-QSAR to analyze the spectral changes of 
phthalates before and after substitution. Yang [26] et al. used DFT to calculate the infrared spectra of 36 polybrominated biphenyl molecules and recorded the highest infrared vibration intensity of each molecule.

DFT can help to obtain either infrared or ultraviolet spectra of QAs. These infrared or ultraviolet spectra information can then feed a 3D-QSAR model as a single-factor input. However, instead of using two single-factor inputs (i.e., infrared spectra intensities and ultraviolet spectra intensities), an infrared-ultraviolet integrated-factor is desired to increase the efficiency and accuracy of a 3D-QSAR model. It is thus essential to introduce an effective method for integrating infrared and ultraviolet spectral characteristics accurately. The fuzzy matter-element analysis theory can serve this purpose. It can solve the multiple parameter evaluation problem of incompatibility through establishing the corresponding matter-element [27]. Yang et al. [28] used the fuzzy matter-element method to assess the water resources carrying capacity of six regions in Huai River, China. Liu and Zou [29] used the fuzzy matter-element evaluation method to assess water quality, obtaining very similar results to the official reported water quality. Compared with the traditional method for superscale calculation, the fuzzy matter-element analysis method has lower workload and would overcome the adverse effects from abnormal values. The integration of fuzzy matter-element method and 3D-QSAR models has a great potential for generating more accurate results, though the topic has not been tackled in previous studies.

In this study, 24 QAs were selected to build the 3D-QSAR models, and among them, marbofloxacin and levofloxacin were selected as the target molecules to be modified. DFT was used obtain infrared and ultraviolet spectra intensities of 24 QAs. The fuzzy matter-element method was adopted to deal with the magnitude of single spectrum (infrared spectral intensity (IRI) and ultraviolet spectral intensity (UVI)) intensities, and the combined effect (CI) values that were obtained. In addition, a 3D-QSAR model based on CI was constructed, and the substituted sites of QAs (improving the CI values) were precisely obtained based on the contour map. The associated CI, IRI, and UVI were investigated and compared. Eventually, the stability, functionality (genetic toxicity), and environmental friendliness (bioaccumulation and biodegradability) of all QA derivatives were evaluated in order to generate more environmentally friendly QA derivatives. This study considers both functionality and environmental friendliness of QA derivatives which leads to a tool for a generation of new antibiotics in the future.

\section{Materials and Methods}

\subsection{Data Sources}

The theoretical calculations of the infrared and ultraviolet spectra of the 24 QAs studied in this paper are based on Gaussian-09 software (Gaussian Inc., Wallingford, CT, USA). Gaussian is the most widely used software package for computational and quantum chemistry [30]. Gaussian can be used to process larger molecular weight structures such as anthraquinone, polyhydroxylated anthroquinones, and polyfluorinated dibenzo-p-dioxins for research and calculation $[24,31]$. DFT is a classical computational method of electronic structure theory which has been frequently used [31]. In most DFT calculations today, the combination of Gaussian orbits is commonly used to represent atomic orbits [32]. The infrared spectrum and ultraviolet spectrum are optimized for the structure of QAs in a gaseous environment at the B3LYP/6-311G (d) level. The infrared spectrum is the optimal structure and its value is calculated and corrected by a correction factor of 0.9614 . The ultraviolet spectrum is based on the optimized ground-state and excited-state geometry, calculated using the DFT method [32].

\subsection{Calculation of the CI Based on Fuzzy Matter-Element Method}

\subsubsection{Construction of Composite Fuzzy Matter-Element Matrix about QAs' CI}

The elementary elements of an ordered triad $\mathrm{R}=(M, C, q)$ are described by the three matter-elements: quinolones $(M)$, detection type $(C)$, and spectral intensity $(q)$ [33]. There are two types of detection 
methods of quinolone $M$ : infrared spectrum $\left(C_{1}\right)$ and ultraviolet spectrum $\left(C_{2}\right)$, corresponding spectral intensities $q_{1}, q_{2}, \ldots, q_{24}$, and $R$ is called $\mathrm{m}$-dimensional fuzzy matter-element. When all the quantities in the composite matter-element $\left(R_{m}\right)$ have ambiguity, then $R_{m}$ is called a composite fuzzy matter-element and can be recorded as:

$$
R_{m n}=\left[\begin{array}{cccc}
M_{1} & M_{2} & \cdots & M_{24} \\
C_{1} q_{11} & q_{12} & \cdots & q_{124} \\
C_{2} q_{21} & q_{22} & \cdots & q_{224}
\end{array}\right]
$$

where $R_{m n}$ is m dimensional matter-element for 24 QAs, $C_{j}$ is the detection type of $j$-th characteristic $(j$ $=1,2), M_{i}$ the $i$-th molecule $(i=1,2, \ldots, 24), q_{i j}$ is the $i$-th spectral intensity corresponding to the $j$-th detection type of a molecule.

\subsubsection{Determination of Subordination Membership Degree of QAs' CI}

The subordination membership degree indicates the fuzzy value corresponding to the single effect parameter of the infrared and ultraviolet spectrums belonging to the standard value of each single effect parameter. The degree of membership is represented by $\eta_{i j}$. The fuzzy matter-element matrix $R_{m n}^{\prime}$ of the preferential membership can be written as:

$$
R_{m n}^{\prime}=\left[\begin{array}{cccc}
M_{1} & M_{2} & \cdots & M_{24} \\
C_{1} \eta_{11} & \eta_{12} & \cdots & \eta_{124} \\
C_{2} \eta_{21} & \eta_{22} & \cdots & \eta_{224}
\end{array}\right]
$$

where $R_{m n}^{\prime}$ is the priority membership fuzzy matter-element; $\eta_{i j}$ is the priority membership of the $j$-th detection type of the $i$-th molecule belonging to the standard sample, $i=1,2, \ldots, 24 ; j=1,2$. The priority membership can be recorded as:

$$
\left\{\begin{array}{l}
\eta_{i j}=\frac{q_{i j}}{\operatorname{Max}_{i j}} \text { (higher is the better) } \\
\eta_{i j}=\frac{\operatorname{Min}_{i j}}{q_{i j}} \text { (lower is the better) }
\end{array}\right.
$$

where $M a x q_{i j}$ represents the maximum value of the spectral intensity in each detection type corresponding to each molecule; $M i n q_{i j}$ represents the minimum value of the spectral intensity in each detection type corresponding to each molecule. It is easier to detect the effect of infrared and ultraviolet spectra, when the value of the effects is larger. Therefore, the largest index will be used for further calculation.

\subsubsection{Determination of Standard Fuzzy Matter-Element and Variance Compound Fuzzy} Matter-Element Matrix for the CI of QAs' IRI and UVI

The m-dimensional standard fuzzy matter-element $R_{0 m}$ is the maximum or minimum value of the spectral strength of the superiority of the spectral intensity in each detection type in the fuzzy matter-of-priority membership. The form is as follows:

$$
R_{0 m}=\left[\begin{array}{c}
M_{0} \\
C_{1} \eta_{01} \\
C_{2} \eta_{02}
\end{array}\right]
$$

where $M_{0}$ represents the standard sample; $\eta_{0 j}$ represents the maximum value of the membership degree of the $j$-th detection type.

$R_{\Delta}$ of variance compound fuzzy matter element can be written as:

$$
R_{\Delta}=\left[\begin{array}{cccc}
M_{1} & M_{2} & \cdots & M_{24} \\
C_{1} \Delta_{11} & \Delta_{12} & \cdots & \Delta_{124} \\
C_{2} \Delta_{21} & \Delta_{22} & \cdots & \Delta_{224}
\end{array}\right]
$$


where $\Delta_{i j}=\left(\eta_{0 j}-\eta_{i j}\right)^{2}$; because the largest subordination membership degree of this paper is the most optimum, $\eta_{0 j}$ equals to 1.

\subsubsection{Determination of Weighting for Evaluation Index of the CI of QAs' IRI and UVI}

The weight determination methods include a subjective weighting approach and objective weighting approach [34]. The subjective weighting approach in this paper uses the empirical method and the objective weighting approach uses the entropy method. The entropy method is calculated according to the following steps:

(1) Construct a judgment matrix $R$ for the infrared spectrum and ultraviolet spectrum of 24 QAs, and normalize $R$ to obtain a normalized judgment matrix A. Determine the entropy of the $j$-th detection type according to the definition of entropy:

$$
S_{j}=\frac{1}{\ln n}\left\{\sum_{i=1}^{n}\left[\frac{1+a_{i j}}{\sum_{i=1}^{n}\left(1+a_{i j}\right)} \ln \frac{1+a_{i j}}{\sum_{i=1}^{n}\left(1+a_{i j}\right)}\right]\right\}(i=1,2, \ldots, 24 ; j=1,2)
$$

where $S_{j}$ is the entropy of the $j$-th detection type; $a_{i j}$ is the fuzzy value of each item in the normalized judgment matrix.

(2) Calculate the entropy weighting of each detection type, it can be recorded as follows:

$$
w_{j}=\frac{1-S_{j}}{m-\sum_{j=1}^{m} S_{j}}\left(0 \leq w_{j} \leq 1, \sum_{j=1}^{m} w_{j}=1\right)
$$

where $w_{j}$ is the entropy of the $j$-th detection type, $j=1,2$.

(3) Determine the comprehensive weights of the comprehensive effect parameters of QAs' infrared and ultraviolet spectra:

The objective weighting $w_{j}$ determined by the entropy method is combined with the subjective weighting $\theta_{j}$ determined by the empirical method. The comprehensive weighting $w_{j}^{\prime}$ of each detection type is finally determined as:

$$
w^{\prime}{ }_{j}=\xi \theta_{j}+(1-\xi) w_{j}(j=1,2)
$$

where $\xi$ is the preference coefficient of the subjective weighting $\xi \in[0,1]$. A larger $\xi$ value indicates that the research focuses more on subjective weighting; conversely, a lower $\xi$ indicates that decision makers should pay more attention to objective weighting.

\subsubsection{Euclidean Closeness Calculation for the CI of QAs' IRI and UVI}

The Euclidean closeness was used to comprehensively analyze the infrared and ultraviolet spectra of 24 QAs. The calculation formula of Euclidean closeness $e_{i}$ can be determined as follows:

$$
e_{i}=1-\sqrt{\sum_{j=1}^{m} w_{j}^{\prime} \Delta_{i j}}(i=1,2, \ldots, 24 ; j=1,2)
$$

\subsection{Construction of $3 D-Q S A R$ Model to Generate Environmentally Friendly QAs}

Based on the database generated from Section 2.2, a 3D-QSAR model was constructed in this paper. The 3D-QSAR analysis was performed using SYBYL-X2.0 software (Tripos Company, St. Louis, USA) [35]. The comprehensive effects of infrared and ultraviolet spectra of 24 QAs were calculated based on the fuzzy matter-element method. When calculating the parameters of the CoMFA field, partial least squares (PLS) analysis was used to establish the relationship between the structure of the target compound and the biological activity [36]. When using PLS analysis, the Leave-One-Out method was used to cross-validate the training set compounds and calculate the cross-validation coefficient $q^{2}$ and the number of optimal principal components $n$ [37]. Non-cross-validation regression (No Validation) was then used to perform regression analysis and calculate the non-cross-validation 
coefficient $r^{2}$, standard deviation SEE, and test value $F$, in order to complete the establishment of the CoMFA model [38]. In addition, single-effect models of infrared and ultraviolet spectra also follow the above operations to construct CoMFA models of single-effects of infrared and ultraviolet spectra of QAs.

\section{Results and Discussion}

\subsection{Calculation of $Q A s^{\prime} I R I$ and UVI based on DFT}

There are many types of QAs, many of which have different behavioral characteristics and hazards in the environment. Therefore, determining the types of QAs that exist in the environment and extracting spectral information assists prediction and evaluation of the magnitude of the hazards caused by such substances to the environment. In this study, the UVI of 24 QAs were obtained using the DFT method based on the optimized ground-state and excited-state geometry. The IRI of 24 QAs were calculated using the Gaussian 09 software with a correction factor of 0.9614 . The intensities of both the infrared and ultraviolet spectrum were optimized in a gaseous environment at the B3LYP/6-311G (d) level. Table 1 lists the calculation results of infrared and ultraviolet spectral intensities of 24 QAs.

Table 1. Infrared spectral intensity (IRI) and ultraviolet spectral intensity (UVI) of 24 quinolone antibiotics (QAs).

\begin{tabular}{cccc}
\hline No. & Name & IRI & UVI \\
\hline Compound 1 & Difloxacin & 1924.76 & 2829.18 \\
Compound 2 & Enrofloxacin & 1289.58 & 4394.34 \\
Compound 3 & Norfloxacin & 1180.48 & 4627.19 \\
Compound 4 & Lomefloxacin & 1788.98 & 1950.61 \\
Compound 5 & Ofloxacin & 1428.91 & 3692.38 \\
Compound 6 & Pefloxacin & 1587.11 & 3542.25 \\
Compound 7 & Fleroxacin & 1882.42 & 1842.68 \\
Compound 8 & Ciprofloxacin & 1247.65 & 4045.59 \\
Compound 9 & Balofloxacin & 1368.19 & 3220.34 \\
Compound 10 & Marbofloxacin & 1265.41 & 264.82 \\
Compound 11 & Pipemidic acid & 2430.36 & 2563.72 \\
Compound 12 & Cinoxacin & 1631.51 & 9680.14 \\
Compound 13 & Enoxacin & 3427.59 & 8254.09 \\
Compound 14 & Gatifloxacin & 1363.79 & 2835.67 \\
Compound 15 & Levofloxacin & 1943.37 & 575.6 \\
Compound 16 & Rufloxacin & 1015.14 & 437.85 \\
Compound 17 & Pazufloxacin & 800.37 & 4259.61 \\
Compound 18 & Nadifloxacin & 1623.96 & 2878.37 \\
Compound 19 & Sparfloxacin & 1185.52 & 2542.11 \\
Compound 20 & Sarafloxacin & 1539.67 & 2605.82 \\
Compound 21 & Besifloxacin & 1682.72 & 3943.26 \\
Compound 22 & Clinafloxacin & 1571.06 & 4875.36 \\
Compound 23 & Grepafloxacin & 1489.4 & 2390.87 \\
Compound 24 & Temafloxacin & 2155.95 & 8643.35 \\
\hline
\end{tabular}

\subsection{Determination of CI of QAs' IRI and UVI Based on Fuzzy Matter-Element Method}

3.2.1. Subordination Membership Degree, Standard Fuzzy Matter-Element and Variance Compound Fuzzy Matter-Element Matrix

Two characteristics of QAs, infrared and ultraviolet spectrums, were applied and the associated fuzzy membership degree, standard fuzzy matter-element and variance composite fuzzy matter-element matrix of the two spectral intensities were calculated using the fuzzy matter-element method according to Equations (1)-(9). The calculation results are summarized in Table 2, which were used to further calculate the CI of QAs. 
Table 2. The results of fuzzy membership, standard fuzzy matter-element and variance compound fuzzy matter-element matrix QAs.

\begin{tabular}{ccccccc}
\hline \multirow{2}{*}{$\boldsymbol{M}_{\boldsymbol{i}}$} & \multicolumn{2}{c}{$\boldsymbol{R}_{\boldsymbol{m} \boldsymbol{n}}^{\prime}$} & \multicolumn{2}{c}{$\boldsymbol{R}_{\boldsymbol{\Delta}}$} & \multicolumn{2}{c}{ Normalization } \\
\cline { 2 - 7 } & $\boldsymbol{C}_{\mathbf{1}}$ & $\boldsymbol{C}_{\mathbf{2}}$ & $\boldsymbol{C}_{\mathbf{1}}$ & $\boldsymbol{C}_{\mathbf{2}}$ & $\boldsymbol{C}_{\mathbf{1}}$ & $\boldsymbol{C}_{\mathbf{2}}$ \\
\hline$M_{1}$ & 0.5615 & 0.2923 & 0.1922 & 0.5009 & 0.4280 & 0.2724 \\
$M_{2}$ & 0.3762 & 0.4540 & 0.3891 & 0.2982 & 0.1862 & 0.4386 \\
$M_{3}$ & 0.3444 & 0.4780 & 0.4298 & 0.2725 & 0.1447 & 0.4633 \\
$M_{4}$ & 0.5219 & 0.2015 & 0.2285 & 0.6376 & 0.3763 & 0.1790 \\
$M_{5}$ & 0.4169 & 0.3814 & 0.3400 & 0.3826 & 0.2392 & 0.3640 \\
$M_{6}$ & 0.4630 & 0.3659 & 0.2883 & 0.4020 & 0.2995 & 0.3481 \\
$M_{7}$ & 0.5492 & 0.1904 & 0.2032 & 0.6555 & 0.4119 & 0.1676 \\
$M_{8}$ & 0.3640 & 0.4179 & 0.4045 & 0.3388 & 0.1702 & 0.4016 \\
$M_{9}$ & 0.3992 & 0.3327 & 0.3610 & 0.4453 & 0.2161 & 0.3139 \\
$M_{10}$ & 0.3692 & 0.0274 & 0.3979 & 0.9460 & 0.1770 & 0.0000 \\
$M_{11}$ & 0.7091 & 0.2648 & 0.0846 & 0.5405 & 0.6204 & 0.2442 \\
$M_{12}$ & 0.4760 & 1.0000 & 0.2746 & 0.0000 & 0.3164 & 1.0000 \\
$M_{13}$ & 1.0000 & 0.8527 & 0.0000 & 0.0217 & 1.0000 & 0.8485 \\
$M_{14}$ & 0.3979 & 0.2929 & 0.3625 & 0.4999 & 0.2145 & 0.2730 \\
$M_{15}$ & 0.5670 & 0.0595 & 0.1875 & 0.8846 & 0.4351 & 0.0330 \\
$M_{16}$ & 0.2962 & 0.0452 & 0.4954 & 0.9116 & 0.0817 & 0.0184 \\
$M_{17}$ & 0.2335 & 0.4400 & 0.5875 & 0.3136 & 0.0000 & 0.4243 \\
$M_{18}$ & 0.4738 & 0.2973 & 0.2769 & 0.4937 & 0.3135 & 0.2776 \\
$M_{19}$ & 0.3459 & 0.2626 & 0.4279 & 0.5437 & 0.1466 & 0.2419 \\
$M_{20}$ & 0.4492 & 0.2692 & 0.3034 & 0.5341 & 0.2814 & 0.2486 \\
$M_{21}$ & 0.4909 & 0.4074 & 0.2591 & 0.3512 & 0.3358 & 0.3907 \\
$M_{22}$ & 0.4584 & 0.5036 & 0.2934 & 0.2464 & 0.2933 & 0.4897 \\
$M_{23}$ & 0.4345 & 0.2470 & 0.3198 & 0.5670 & 0.2623 & 0.2258 \\
$M_{24}$ & 0.6290 & 0.8929 & 0.1376 & 0.0115 & 0.5160 & 0.8899 \\
\hline & & & & & &
\end{tabular}

\subsubsection{Comprehensive Weightings for CI of QAs' IRI and UVI}

The data of the infrared and ultraviolet spectra of QAs are derived from the results of DFT calculations in quantum chemical calculations. Both detection methods have shown similar physical significance when detecting quinolones [39,40]. Therefore, the subjective weighting for both infrared and ultraviolet spectra was set as 0.5 . In addition, the obtained data was normalized before calculating the objective weightings. The specific results are shown in Table 3.

Table 3. The results of objective weightings and comprehensive weightings of QAs' infrared and ultraviolet spectra.

\begin{tabular}{cccccc}
\hline \multicolumn{2}{c}{ Entropy } & \multicolumn{2}{c}{ Entropy Weights } & \multicolumn{2}{c}{ Comprehensive Weights } \\
\hline$S_{\mathbf{1}}$ & $\boldsymbol{S}_{\mathbf{2}}$ & $\boldsymbol{W}_{\mathbf{1}}$ & $\boldsymbol{W}_{\mathbf{2}}$ & $\boldsymbol{W}_{\mathbf{1}}$ & $\boldsymbol{W}_{\mathbf{2}}$ \\
\hline-0.9966 & -0.9950 & 0.5002 & 0.4998 & 0.5001 & 0.4999 \\
\hline
\end{tabular}

From the results, it can be seen that the objective weights calculated by the entropy method are 0.5002 and 0.4998 , and the comprehensive weights are 0.5001 and 0.4999 , which are close to 0.5 .

\subsubsection{CI of QAs' IRI and UVI}

In this study, the Euclidean closeness was calculated by using Equation (9) with the processed single-effect parameters of 24 QAs representing the comprehensive effects of infrared and ultraviolet spectra of these QAs. As presented in Table 4, the CI values obtained based on the fuzzy matter-element method varied from 0.1613 to 0.8958 . The dynamic range of the CI values is 5.6, greater than that stated in previous studies [41-45]. It indicated that the CI data set of QAs' IRI and UVI could be employed to build the associated 3D-QSAR model based on the comprehensive effect. 
Table 4. Calculation of comprehensive effects of infrared and ultraviolet spectra of 24 QAs based on fuzzy matter-element method.

\begin{tabular}{cccccc}
\hline $\boldsymbol{e}_{\mathbf{i}}$ & Comprehensive Effects & $\boldsymbol{e}_{\mathbf{i}}$ & Comprehensive Effects & $\boldsymbol{e}_{\mathbf{i}}$ & Comprehensive Effects \\
\hline$e_{1}$ & 0.4113 & $e_{9}$ & 0.3651 & $e_{17}$ & 0.3288 \\
$e_{2}$ & 0.4138 & $e_{10}$ & 0.1803 & $e_{18}$ & 0.3793 \\
$e_{3}$ & 0.4074 & $e_{11}$ & 0.4409 & $e_{19}$ & 0.3030 \\
$e_{4}$ & 0.3419 & $e_{12}$ & 0.6295 & $e_{20}$ & 0.3529 \\
$e_{5}$ & 0.3989 & $e_{13}$ & 0.8958 & $e_{21}$ & 0.4476 \\
$e_{6}$ & 0.4125 & $e_{14}$ & 0.3433 & $e_{22}$ & 0.4805 \\
$e_{7}$ & 0.3447 & $e_{15}$ & 0.2678 & $e_{23}$ & 0.3341 \\
$e_{8}$ & 0.3904 & $e_{16}$ & 0.1613 & $e_{24}$ & 0.7269 \\
\hline
\end{tabular}

\subsection{Construction and Evaluation of 3D-QSAR Model Based on CI of QAs' IRI and UVI}

\subsubsection{Construction of the 3D-QSAR Model}

The CI of 16 QAs were randomly selected as data sources. Temafloxacin with the highest CI $\left(e_{24}\right.$ $=0.7296$ ) was chosen as the target molecule, 13 QAs as the training set, and the remaining 4 QAs as the testing set (Temafloxacin exists in both the training set and the testing set). Based on these comprehensive effects, a 3D-QSAR model was constructed. SYBYL-X2.0 (Tripos Company, USA) was used in this study to select the lowest energy conformation of the molecule as the dominant stable conformation, and G-H electrical charges (Gasteiger-Huckel) were loaded. The maximum number of optimizations was 10,000 using the Powell energy gradient method, and the energy convergence was limited to $0.005 \mathrm{~kJ} / \mathrm{mol}[46,47]$. The optimized molecules were stored in the database for alignment. All molecules were aligned with the pharmacophore characteristic elements in the marked area shown in Figure 1 as the basic skeleton. The structures of selected target molecules, marbofloxacin and levofloxacin are also shown in Figure 1. The CoMFA module will be used to establish the infrared and ultraviolet spectra suitable for QAs by using the basic skeleton for comprehensive effects prediction.

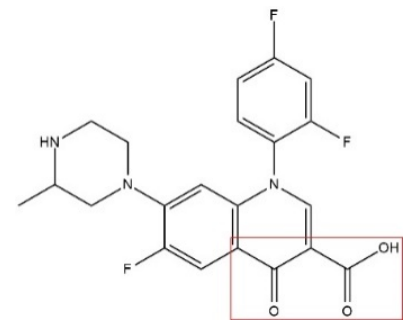

(a)

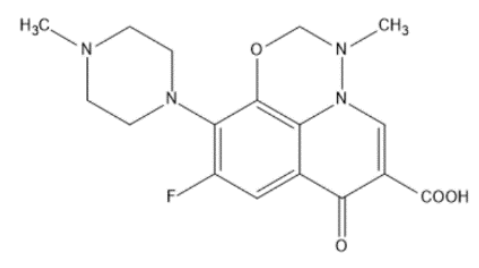

(b)

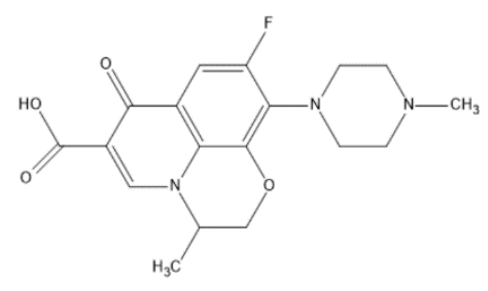

(c)

Figure 1. (a) Molecular structure and common skeleton of Temafloxacin; (b) molecular structure of marbofloxacin; (c) molecular structure of levofloxacin.

\subsubsection{Performance Evaluation of the 3D-QSAR Model}

The evaluation results of 3D-QSAR model show that in the CoMFA model, the cross-validation coefficient $q^{2}$ is $0.67\left(q^{2}>0.5\right)$, and the best principal component $n$ is 3 , indicating that the model has a good prediction ability. The cross-validation coefficient $R^{2}$ is $0.984(>0.9)$, the standard error of estimate (SEE) is 0.023 , and the F-test value is 179.271 , indicating that the model has a good ability to fit and predict [48].

Golbraikh and Ropsha [49] confirmed that the strict QSAR model verification procedures should include internal and external verification. The use of internal verification parameters such as $q^{2}$ cannot assess the quality of the model. Therefore, external verification methods need to be applied. External verification methods are one of the most valuable verification methods, and were applied to evaluate the predictive ability of the obtained model. The overall predictive ability of the CoMFA model was externally verified by predicting the activity of the compounds in the independent testing set [49]. The 
predictive ability of the model is represented by the predicted $r^{2}$ pred, and its calculation formula is as follows:

$$
r_{\text {pred }}^{2}=1-\frac{P R E S S}{S D}
$$

In the formula, PRESS refers to the sum of the squared deviations between the calculated and predicted values in the test set, and $S D$ refers to the sum of the squared deviations between the calculated values of the compounds in the test set and the average values of the calculated values of the compounds in the training set.

The constructed CoMFA model was used to predict the activity of the test set molecules, and external verification was performed based on the prediction results (Table 5). The results show that the interaction test coefficient $r^{2}$ pred of the external prediction set is 0.9695 (>0.6) [50]. Tropsha method was also used to evaluate the external prediction ability of this model. The calculation results indicated that $\mathrm{r}$ was $0.9932, \mathrm{r}^{2}$ was $0.9864(>0.6)$, $\mathrm{k}$ was $1.0269(0.85<\mathrm{k}<1.15)$, $\mathrm{k}^{\prime}$ was $0.9712\left(0.85<\mathrm{k}^{\prime}<1.15\right), \mathrm{r}_{0}{ }^{2}$ was 0.893, and $\mathrm{r}_{0^{\prime}}{ }^{2}$ was 0.932. Furthermore, $\left(\mathrm{r}^{2}-\mathrm{r}_{0}{ }^{2}\right) / \mathrm{r}^{2}=-0.0060(<0.1)$ and $\left(\mathrm{r}^{2}-\mathrm{r}_{0^{\prime}}{ }^{2}\right) / \mathrm{r}^{2}=0.0115(<0.1)$ The above parameters all met the external verification requirements [51,52], therefore, the constructed 3D-QSAR model has shown a satisfactory external prediction capability.

Table 5. The predicted combined effects of infrared and ultraviolet spectra (CI) of QAs using Comparative Molecular Field Analysis (CoMFA) model.

\begin{tabular}{cccc}
\hline No. & Calculated Value & Predicted Value & Relative Deviation \\
\hline a Compound 3 & 0.4074 & 0.3990 & $2.06 \%$ \\
a Compound 4 & 0.3419 & 0.3540 & $-3.54 \%$ \\
${ }^{\text {b Compound 7 }}$ & 0.3447 & 0.3970 & $-15.17 \%$ \\
a Compound 8 & 0.3904 & 0.4170 & $-6.81 \%$ \\
a Compound 9 & 0.3651 & 0.3620 & $0.85 \%$ \\
${ }^{a}$ Compound 10 & 0.1803 & 0.1630 & $9.60 \%$ \\
a Compound 11 & 0.4409 & 0.4430 & $-0.48 \%$ \\
${ }^{a}$ Compound 12 & 0.6295 & 0.6520 & $-3.57 \%$ \\
${ }^{a}$ Compound 15 & 0.2678 & 0.2680 & $-0.07 \%$ \\
a Compound 16 & 0.1613 & 0.1950 & $-20.89 \%$ \\
${ }^{b}$ Compound 18 & 0.3793 & 0.3800 & $-0.18 \%$ \\
b Compound 20 & 0.3529 & 0.3770 & $-6.83 \%$ \\
a Compound 21 & 0.4476 & 0.4300 & $3.93 \%$ \\
a Compound 22 & 0.4805 & 0.4390 & $8.64 \%$ \\
a Compound 23 & 0.3341 & 0.3290 & $1.53 \%$ \\
a,b Compound 24 & 0.7269 & 0.7240 & $0.40 \%$ \\
\hline
\end{tabular}

a Training set; ${ }^{\mathrm{b}}$ Test set.

\subsection{Determination of Substitution Characteristics Based on the Contour Maps}

In the CoMFA model, the contributions of the steric and electrostatic fields are $68.10 \%$ and $31.90 \%$, respectively, suggesting that the steric effect and electrical distribution of the groups will affect CI of QAs. In the steric field, the green area indicates that the introduction of bigger molecular groups in this area can improve the CI of QAs, while the yellow area indicates that the introduction of bigger molecular groups in this area can reduce the comprehensive effect of QAs. In the electrostatic field, the blue area indicates that the addition of positive groups is beneficial to improve the CI of QAs, and the red area indicates that the addition of negative groups is beneficial to the comprehensive effect of QAs.

This study uses marbofloxacin and levofloxacin as examples to modify the substituents at positions $1\left(\mathrm{CH}_{3}\right)$ and $2\left(\mathrm{CH}_{3}\right)$, respectively. From the contour maps of marbofloxacin, it can be seen that the area near the 1-position substituent is mainly blue, indicating that the introduction of a positive group at the 1-position substituent is beneficial to improve the QAs' CI; the green and red regions near the substituent at position 2 indicate that the introduction of bigger molecular groups and negative groups 
at the substituent in this position is conducive to improving the comprehensive effect value of the infrared and ultraviolet spectra of QAs. From the contour maps of levofloxacin, it can be seen that the vicinity of the substituent at position 1 is mainly blue, indicating that the introduction of a positively charged group at the substituent in this position is beneficial to improve the CI of QAs. The regions near the 2-position substituent are mainly green and red, indicating that the introduction of bigger molecular groups and negative groups at the 2-position substituent is conducive to improving the CI of QAs (Figure 2).

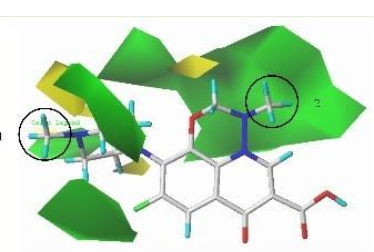

(a)

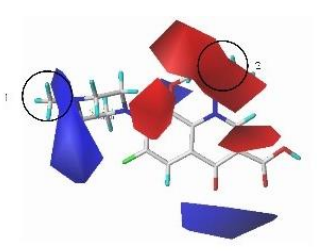

(b)

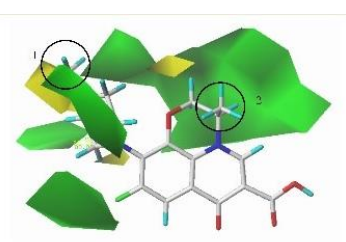

(c)

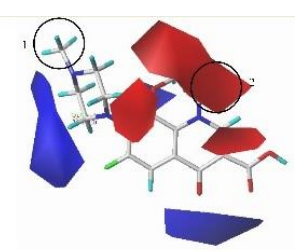

(d)

Figure 2. The contour maps of (a) Marbofloxacin (steric field), (b) marbofloxacin (electrostatic field), (c) levofloxacin (steric field), (d) levofloxacin (electrostatic field)

In summary, the 1- and 2-position substituents of marbofloxacin and levofloxacin were modified, respectively. Among them, positive groups $\left(-\mathrm{H},-\mathrm{SiH}_{3},-\mathrm{C}_{2} \mathrm{H}_{5},-\mathrm{PH}_{2},-\mathrm{C}_{3} \mathrm{H}_{7},-\mathrm{C}_{4} \mathrm{H}_{9},-\mathrm{C}_{5} \mathrm{H}_{11}\right)$ can be introduced at the 1-position substituent of marbofloxacin, and bigger molecular groups and negative groups $\left(-\mathrm{CH}_{2} \mathrm{~F},-\mathrm{C}_{2} \mathrm{H}_{3},-\mathrm{C}_{2} \mathrm{H},-\mathrm{CH}_{2} \mathrm{OH},-\mathrm{NH}_{2},-\mathrm{NO},-\mathrm{NO}_{2},-\mathrm{CHO},-\mathrm{COOH}\right)$ can be introduced at the 2-position substituent. A total of 13 single-substituted marbofloxacin derivatives and 57 double-substituted marbofloxacin derivatives. Positive groups $\left(-\mathrm{H},-\mathrm{SiH}_{3},-\mathrm{C}_{2} \mathrm{H}_{5},-\mathrm{C}_{3} \mathrm{H}_{7},-\mathrm{C}_{4} \mathrm{H}_{9}\right.$, $-\mathrm{C}_{5} \mathrm{H}_{11}$ ) can be introduced at the 1-position substituent of levofloxacin, and bigger molecular groups and negative charged group $\left(-\mathrm{C}_{2} \mathrm{H}_{3},-\mathrm{NO},-\mathrm{NO}_{2},-\mathrm{OCH}_{3},-\mathrm{OH},-\mathrm{CN}\right)$ can be introduced at the 2-position substituent. A total of four single-substituted levofloxacin derivatives and 13 double-substituted levofloxacin derivatives. Thus, a total of $87 \mathrm{QA}$ derivatives were generated. The molecular structures of these derivatives are shown in Table S1.

\subsection{Evaluation of Molecular Spectral Characteristics, Functional Characteristics, Environmental Friendliness,} and Stability of the QA Derivatives

\subsubsection{Molecular Spectral Characteristics}

In this paper, the 3D-QSAR model was used to evaluate the CI of 87 QA derivatives. In addition, a single-effect model of infrared spectrum and ultraviolet spectrum was established in order to further verify the feasibility and rationality of the fuzzy matter-element method. Therefore, the single-effect model was used to evaluate the infrared spectrum intensity and ultraviolet spectrum single-effect of 87 QA derivatives (Table 6).

By analyzing the data in Table 6, it can be seen that when the comprehensive effects of 87 QA derivatives were enhanced, the single effects of the IRI and UVI were also enhanced. The average value of the comprehensive effect enhancement range was $186.46 \%$, the average value of the single-effect enhancement amplitude of the infrared spectrum was $69.45 \%$, and the average value of the single-effect enhancement amplitude of the ultraviolet spectrum was $1398.39 \%$. Figure S1 was further generated to reflect the relationship between each QA structure and the associated activities (i.e., IRI, UVI, and CI) with marbofloxacin and levofloxacin used as the target molecules. Results indicated that the molecular design of QA derivatives showed positive effect on all activities with obvious enhancement of IRI, UVI, and $C I$ values. 
Table 6. The predicted evaluation of 87 QA derivatives' molecular spectral characteristic.

\begin{tabular}{|c|c|c|c|c|c|c|c|c|}
\hline \multirow[t]{2}{*}{ QA Derivatives } & \multicolumn{2}{|c|}{$\begin{array}{c}\text { Position of } \\
\text { Substitution }\end{array}$} & \multirow[t]{2}{*}{$\mathrm{CI}$} & \multirow[t]{2}{*}{ Relative Deviation } & \multirow[t]{2}{*}{ IRI } & \multirow[t]{2}{*}{ Relative Deviation } & \multirow[t]{2}{*}{ UVI } & \multirow[t]{2}{*}{ Relative Deviation } \\
\hline & 1-Position & 2-Position & & & & & & \\
\hline Marbofloxacin & $\mathrm{CH}_{3}$ & $\mathrm{CH}_{3}$ & 0.1803 & & 1265.4100 & & 264.8200 & \\
\hline Derivative 1 & $\mathrm{SiH}_{3}$ & - & 0.2820 & $56.41 \%$ & 2046.4446 & $61.72 \%$ & 920.4496 & $247.58 \%$ \\
\hline Derivative 2 & $\mathrm{C}_{2} \mathrm{H}_{5}$ & - & 0.2690 & $49.20 \%$ & 2128.1390 & $68.18 \%$ & 749.8942 & $183.17 \%$ \\
\hline Derivative 3 & $\mathrm{PH}_{2}$ & - & 0.2850 & $58.07 \%$ & 2051.1622 & $62.09 \%$ & 916.2205 & $245.98 \%$ \\
\hline Derivative 4 & $\mathrm{C}_{3} \mathrm{H}_{7}$ & - & 0.2690 & $49.20 \%$ & 2113.4890 & $67.02 \%$ & 711.2135 & $168.56 \%$ \\
\hline Derivative 5 & $\mathrm{C}_{4} \mathrm{H}_{9}$ & - & 0.2690 & $49.20 \%$ & 2133.0449 & $68.57 \%$ & 714.4963 & $169.80 \%$ \\
\hline Derivative 6 & $\mathrm{C}_{5} \mathrm{H}_{11}$ & - & 0.2690 & $49.20 \%$ & 2133.0449 & $68.57 \%$ & 712.8530 & $169.18 \%$ \\
\hline Derivative 7 & - & $\mathrm{CH}_{2} \mathrm{~F}$ & 0.3510 & $94.68 \%$ & 2051.1622 & $62.09 \%$ & 1492.7944 & $463.70 \%$ \\
\hline Derivative 8 & - & $\mathrm{C}_{2} \mathrm{H}_{3}$ & 0.3210 & $78.04 \%$ & 2023.0192 & $59.87 \%$ & 1205.0359 & $355.04 \%$ \\
\hline Derivative 9 & - & $\mathrm{C}_{2} \mathrm{H}$ & 0.3100 & $71.94 \%$ & 1976.9696 & $56.23 \%$ & 805.3784 & $204.12 \%$ \\
\hline Derivative 10 & - & $\mathrm{CH}_{2} \mathrm{OH}$ & 0.2930 & $62.51 \%$ & 2013.7242 & $59.14 \%$ & 972.7472 & $267.32 \%$ \\
\hline Derivative 11 & - & $\mathrm{NH}_{2}$ & 0.3030 & $68.05 \%$ & 2051.1622 & $62.09 \%$ & 629.5062 & $137.71 \%$ \\
\hline Derivative 12 & - & $\mathrm{NO}$ & 0.3530 & $95.78 \%$ & 2009.0928 & $58.77 \%$ & 1061.6956 & $300.91 \%$ \\
\hline Derivative 13 & - & $\mathrm{NO}_{2}$ & 0.3590 & $99.11 \%$ & 1995.2623 & $57.68 \%$ & 1142.8783 & $331.57 \%$ \\
\hline Derivative 14 & $\mathrm{SiH}_{3}$ & $\mathrm{CH}_{2} \mathrm{~F}$ & 0.3550 & $96.89 \%$ & 2060.6299 & $62.84 \%$ & 1442.1154 & $444.56 \%$ \\
\hline Derivative 15 & $\mathrm{PH}_{2}$ & $\mathrm{CH}_{2} \mathrm{~F}$ & 0.3510 & $94.68 \%$ & 2046.4446 & $61.72 \%$ & 1492.7944 & $463.70 \%$ \\
\hline Derivative 16 & $\mathrm{C}_{3} \mathrm{H}_{7}$ & $\mathrm{CH}_{2} \mathrm{~F}$ & 0.8050 & $346.48 \%$ & 2511.8864 & $98.50 \%$ & 8729.7137 & $3196.47 \%$ \\
\hline Derivative 17 & $\mathrm{C}_{4} \mathrm{H}_{9}$ & $\mathrm{CH}_{2} \mathrm{~F}$ & 0.8060 & $347.03 \%$ & 2511.8864 & $98.50 \%$ & 8729.7137 & $3196.47 \%$ \\
\hline Derivative 18 & $\mathrm{C}_{5} \mathrm{H}_{11}$ & $\mathrm{CH}_{2} \mathrm{~F}$ & 0.8060 & $347.03 \%$ & 2511.8864 & $98.50 \%$ & 8729.7137 & $3196.47 \%$ \\
\hline Derivative 19 & $\mathrm{H}$ & $\mathrm{C}_{2} \mathrm{H}_{3}$ & 0.8150 & $352.02 \%$ & 2624.2185 & $107.38 \%$ & 9571.9407 & $3514.51 \%$ \\
\hline Derivative 20 & $\mathrm{SiH}_{3}$ & $\mathrm{C}_{2} \mathrm{H}_{3}$ & 0.8210 & $355.35 \%$ & 2630.2680 & $107.86 \%$ & 9354.0567 & $3432.23 \%$ \\
\hline Derivative 21 & $\mathrm{C}_{2} \mathrm{H}_{5}$ & $\mathrm{C}_{2} \mathrm{H}_{3}$ & 0.8190 & $354.24 \%$ & 2630.2680 & $107.86 \%$ & 9332.5430 & $3424.11 \%$ \\
\hline Derivative 22 & $\mathrm{PH}_{2}$ & $\mathrm{C}_{2} \mathrm{H}_{3}$ & 0.8180 & $353.69 \%$ & 2630.2680 & $107.86 \%$ & 9506.0479 & $3489.63 \%$ \\
\hline Derivative 23 & $\mathrm{C}_{3} \mathrm{H}_{7}$ & $\mathrm{C}_{2} \mathrm{H}_{3}$ & 0.8210 & $355.35 \%$ & 2636.3314 & $108.34 \%$ & 8356.0302 & $3055.36 \%$ \\
\hline Derivative 24 & $\mathrm{C}_{4} \mathrm{H}_{9}$ & $\mathrm{C}_{2} \mathrm{H}_{3}$ & 0.8210 & $355.35 \%$ & 2636.3314 & $108.34 \%$ & 8298.5077 & $3033.64 \%$ \\
\hline Derivative 25 & $\mathrm{C}_{5} \mathrm{H}_{11}$ & $\mathrm{C}_{2} \mathrm{H}_{3}$ & 0.8210 & $355.35 \%$ & 2654.6056 & $109.78 \%$ & 7870.4579 & $2872.00 \%$ \\
\hline Derivative 26 & $\mathrm{H}$ & $\mathrm{C}_{2} \mathrm{H}$ & 0.8160 & $352.58 \%$ & 2570.3958 & $103.13 \%$ & 9549.9259 & $3506.20 \%$ \\
\hline Derivative 27 & $\mathrm{SiH}_{3}$ & $\mathrm{C}_{2} \mathrm{H}$ & 0.8210 & $355.35 \%$ & 2594.1794 & $105.01 \%$ & 9141.1324 & $3351.83 \%$ \\
\hline Derivative 28 & $\mathrm{C}_{2} \mathrm{H}_{5}$ & $\mathrm{C}_{2} \mathrm{H}$ & 0.8210 & $355.35 \%$ & 2612.1614 & $106.43 \%$ & 8974.2879 & $3288.83 \%$ \\
\hline Derivative 29 & $\mathrm{PH}_{2}$ & $\mathrm{C}_{2} \mathrm{H}$ & 0.8170 & $353.13 \%$ & 2588.2129 & $104.54 \%$ & 9484.1846 & $3481.37 \%$ \\
\hline Derivative 30 & $\mathrm{C}_{3} \mathrm{H}_{7}$ & $\mathrm{C}_{2} \mathrm{H}$ & 0.7960 & $341.49 \%$ & 2588.2129 & $104.54 \%$ & 6180.1640 & $2233.72 \%$ \\
\hline
\end{tabular}


Table 6. Cont

\begin{tabular}{|c|c|c|c|c|c|c|c|c|}
\hline \multirow[t]{2}{*}{ QA Derivatives } & \multicolumn{2}{|c|}{$\begin{array}{c}\text { Position of } \\
\text { Substitution }\end{array}$} & \multirow[t]{2}{*}{ CI } & \multirow[t]{2}{*}{ Relative Deviation } & \multirow[t]{2}{*}{ IRI } & \multirow[t]{2}{*}{ Relative Deviation } & \multirow[t]{2}{*}{ UVI } & \multirow[t]{2}{*}{ Relative Deviation } \\
\hline & 1-Position & 2-Position & & & & & & \\
\hline Derivative 31 & $\mathrm{C}_{4} \mathrm{H}_{9}$ & $\mathrm{C}_{2} \mathrm{H}$ & 0.7960 & $341.49 \%$ & 2588.2129 & $104.54 \%$ & 5807.6442 & $2093.05 \%$ \\
\hline Derivative 32 & $\mathrm{C}_{5} \mathrm{H}_{11}$ & $\mathrm{C}_{2} \mathrm{H}$ & 0.7950 & $340.93 \%$ & 2588.2129 & $104.54 \%$ & 5754.3994 & $2072.95 \%$ \\
\hline Derivative 33 & $\mathrm{H}$ & $\mathrm{CH}_{2} \mathrm{OH}$ & 0.8200 & $354.80 \%$ & 2523.4808 & $99.42 \%$ & 9660.5088 & $3547.95 \%$ \\
\hline Derivative 34 & $\mathrm{SiH}_{3}$ & $\mathrm{CH}_{2} \mathrm{OH}$ & 0.8260 & $358.13 \%$ & 2535.1286 & $100.34 \%$ & 9397.2331 & $3448.54 \%$ \\
\hline Derivative 35 & $\mathrm{C}_{2} \mathrm{H}_{5}$ & $\mathrm{CH}_{2} \mathrm{OH}$ & 0.8250 & $357.57 \%$ & 2535.1286 & $100.34 \%$ & 8749.8378 & $3204.07 \%$ \\
\hline Derivative 36 & $\mathrm{PH}_{2}$ & $\mathrm{CH}_{2} \mathrm{OH}$ & 0.8220 & $355.91 \%$ & 2529.2980 & $99.88 \%$ & 9616.1228 & $3531.19 \%$ \\
\hline Derivative 37 & $\mathrm{C}_{3} \mathrm{H}_{7}$ & $\mathrm{CH}_{2} \mathrm{OH}$ & 0.8230 & $356.46 \%$ & 2523.4808 & $99.42 \%$ & 8933.0548 & $3273.26 \%$ \\
\hline Derivative 38 & $\mathrm{C}_{4} \mathrm{H}_{9}$ & $\mathrm{CH}_{2} \mathrm{OH}$ & 0.8230 & $356.46 \%$ & 2529.2980 & $99.88 \%$ & 8974.2879 & $3288.83 \%$ \\
\hline Derivative 39 & $\mathrm{C}_{5} \mathrm{H}_{11}$ & $\mathrm{CH}_{2} \mathrm{OH}$ & 0.8230 & $356.46 \%$ & 2529.2980 & $99.88 \%$ & 8974.2879 & $3288.83 \%$ \\
\hline Derivative 40 & $\mathrm{H}$ & $\mathrm{NH}_{2}$ & 0.7920 & $339.27 \%$ & 2546.8303 & $101.27 \%$ & 8609.9375 & $3151.24 \%$ \\
\hline Derivative 41 & $\mathrm{SiH}_{3}$ & $\mathrm{NH}_{2}$ & 0.8000 & $343.70 \%$ & 2558.5859 & $102.19 \%$ & 8317.6377 & $3040.86 \%$ \\
\hline Derivative 42 & $\mathrm{C}_{2} \mathrm{H}_{5}$ & $\mathrm{NH}_{2}$ & 0.8020 & $344.81 \%$ & 2582.2602 & $104.07 \%$ & 8336.8118 & $3048.11 \%$ \\
\hline Derivative 43 & $\mathrm{PH}_{2}$ & $\mathrm{NH}_{2}$ & 0.8010 & $344.26 \%$ & 2582.2602 & $104.07 \%$ & 8336.8118 & $3048.11 \%$ \\
\hline Derivative 44 & $\mathrm{C}_{3} \mathrm{H}_{7}$ & $\mathrm{NH}_{2}$ & 0.7720 & $328.18 \%$ & 2594.1794 & $105.01 \%$ & 6123.5039 & $2212.33 \%$ \\
\hline Derivative 45 & $\mathrm{C}_{4} \mathrm{H}_{9}$ & $\mathrm{NH}_{2}$ & 0.3450 & $91.35 \%$ & 2162.7185 & $70.91 \%$ & 2805.4336 & $959.37 \%$ \\
\hline Derivative 46 & $\mathrm{C}_{5} \mathrm{H}_{11}$ & $\mathrm{NH}_{2}$ & 0.3730 & $106.88 \%$ & 2187.7616 & $72.89 \%$ & 2792.5438 & $954.51 \%$ \\
\hline Derivative 47 & $\mathrm{H}$ & $\mathrm{NO}$ & 0.3200 & $77.48 \%$ & 2137.9621 & $68.95 \%$ & 1606.9413 & $506.81 \%$ \\
\hline Derivative 48 & $\mathrm{SiH}_{3}$ & NO & 0.2730 & $51.41 \%$ & 2192.8049 & $73.29 \%$ & 1166.8096 & $340.60 \%$ \\
\hline Derivative 49 & $\mathrm{C}_{2} \mathrm{H}_{5}$ & $\mathrm{NO}$ & 0.2420 & $34.22 \%$ & 2157.7444 & $70.52 \%$ & 984.0111 & $271.58 \%$ \\
\hline Derivative 50 & $\mathrm{PH}_{2}$ & NO & 0.4150 & $130.17 \%$ & 1972.4227 & $55.87 \%$ & 2074.9135 & $683.52 \%$ \\
\hline Derivative 51 & $\mathrm{C}_{3} \mathrm{H}_{7}$ & NO & 0.2440 & $35.33 \%$ & 2128.1390 & $68.18 \%$ & 990.8319 & $274.15 \%$ \\
\hline Derivative 52 & $\mathrm{C}_{4} \mathrm{H}_{9}$ & $\mathrm{NO}$ & 0.2460 & $36.44 \%$ & 2137.9621 & $68.95 \%$ & 933.2543 & $252.41 \%$ \\
\hline Derivative 53 & $\mathrm{C}_{5} \mathrm{H}_{11}$ & NO & 0.2460 & $36.44 \%$ & 2128.1390 & $68.18 \%$ & 937.5620 & $254.04 \%$ \\
\hline Derivative 54 & $\mathrm{H}$ & $\mathrm{NO}_{2}$ & 0.3170 & $75.82 \%$ & 2079.6967 & $64.35 \%$ & 1534.6170 & $479.49 \%$ \\
\hline Derivative 55 & $\mathrm{SiH}_{3}$ & $\mathrm{NO}_{2}$ & 0.2530 & $40.32 \%$ & 2113.4890 & $67.02 \%$ & 1156.1122 & $336.57 \%$ \\
\hline Derivative 56 & $\mathrm{C}_{2} \mathrm{H}_{5}$ & $\mathrm{NO}_{2}$ & 0.2340 & $29.78 \%$ & 2094.1125 & $65.49 \%$ & 1324.3415 & $400.09 \%$ \\
\hline Derivative 57 & $\mathrm{C}_{3} \mathrm{H}_{7}$ & $\mathrm{NO}_{2}$ & 0.2350 & $30.34 \%$ & 2074.9135 & $63.97 \%$ & 918.3326 & $246.78 \%$ \\
\hline Derivative 58 & $\mathrm{C}_{4} \mathrm{H}_{9}$ & $\mathrm{NO}_{2}$ & 0.2360 & $30.89 \%$ & 2089.2961 & $65.11 \%$ & 889.2011 & $235.78 \%$ \\
\hline Derivative 59 & $\mathrm{C}_{5} \mathrm{H}_{11}$ & $\mathrm{NO}_{2}$ & 0.2360 & $30.89 \%$ & 2089.2961 & $65.11 \%$ & 870.9636 & $228.89 \%$ \\
\hline Derivative 60 & $\mathrm{H}$ & $\mathrm{CHO}$ & 0.4500 & $149.58 \%$ & 1981.5270 & $56.59 \%$ & 3019.9517 & $1040.38 \%$ \\
\hline Derivative 61 & $\mathrm{SiH}_{3}$ & $\mathrm{CHO}$ & 0.4110 & $127.95 \%$ & 1896.7059 & $49.89 \%$ & 2488.8573 & $839.83 \%$ \\
\hline
\end{tabular}


Table 6. Cont

\begin{tabular}{|c|c|c|c|c|c|c|c|c|}
\hline \multirow[t]{2}{*}{ QA Derivatives } & \multicolumn{2}{|c|}{$\begin{array}{c}\text { Position of } \\
\text { Substitution }\end{array}$} & \multirow[t]{2}{*}{ CI } & \multirow[t]{2}{*}{ Relative Deviation } & \multirow[t]{2}{*}{ IRI } & \multirow[t]{2}{*}{ Relative Deviation } & \multirow[t]{2}{*}{ UVI } & \multirow[t]{2}{*}{ Relative Deviation } \\
\hline & 1-Position & 2-Position & & & & & & \\
\hline Derivative 62 & $\mathrm{C}_{2} \mathrm{H}_{5}$ & $\mathrm{CHO}$ & 0.3270 & $81.36 \%$ & 1909.8533 & $50.93 \%$ & 1753.8805 & $562.29 \%$ \\
\hline Derivative 63 & $\mathrm{C}_{3} \mathrm{H}_{7}$ & $\mathrm{CHO}$ & 0.3130 & $73.60 \%$ & 1918.6687 & $51.62 \%$ & 1774.1895 & $569.96 \%$ \\
\hline Derivative 64 & $\mathrm{C}_{4} \mathrm{H}_{9}$ & $\mathrm{CHO}$ & 0.3260 & $80.81 \%$ & 1927.5249 & $52.32 \%$ & 2032.3570 & $667.45 \%$ \\
\hline Derivative 65 & $\mathrm{C}_{5} \mathrm{H}_{11}$ & $\mathrm{CHO}$ & 0.3270 & $81.36 \%$ & 1923.0917 & $51.97 \%$ & 2018.3664 & $662.17 \%$ \\
\hline Derivative 66 & $\mathrm{H}$ & $\mathrm{COOH}$ & 0.4550 & $152.36 \%$ & 2065.3802 & $63.22 \%$ & 2951.2092 & $1014.42 \%$ \\
\hline Derivative 67 & $\mathrm{SiH}_{3}$ & $\mathrm{COOH}$ & 0.3960 & $119.63 \%$ & 2074.9135 & $63.97 \%$ & 2301.4418 & $769.06 \%$ \\
\hline Derivative 68 & $\mathrm{C}_{2} \mathrm{H}_{5}$ & $\mathrm{COOH}$ & 0.3170 & $75.82 \%$ & 1995.2623 & $57.68 \%$ & 1923.0917 & $626.19 \%$ \\
\hline Derivative 69 & $\mathrm{C}_{3} \mathrm{H}_{7}$ & $\mathrm{COOH}$ & 0.3030 & $68.05 \%$ & 1986.0949 & $56.95 \%$ & 1905.4607 & $619.53 \%$ \\
\hline Derivative 70 & $\mathrm{C}_{4} \mathrm{H}_{9}$ & $\mathrm{COOH}$ & 0.3130 & $73.60 \%$ & 1986.0949 & $56.95 \%$ & 2108.6281 & $696.25 \%$ \\
\hline Levofloxacin & $\mathrm{CH}_{3}$ & $\mathrm{CH}_{3}$ & 0.2678 & & 1943.3700 & & 575.6000 & \\
\hline Derivative 71 & $\mathrm{C}_{4} \mathrm{H}_{9}$ & & 0.7850 & $193.13 \%$ & 2409.9054 & $24.01 \%$ & 7430.1914 & $1190.86 \%$ \\
\hline Derivative 72 & $\mathrm{C}_{4} \mathrm{H}_{9}$ & $\mathrm{C}_{2} \mathrm{H}_{3}$ & 0.7500 & $180.06 \%$ & 2636.3314 & $35.66 \%$ & 5834.4510 & $913.63 \%$ \\
\hline Derivative 73 & $\mathrm{C}_{3} \mathrm{H}_{7}$ & $\mathrm{OH}$ & 0.7430 & $177.45 \%$ & 2552.7013 & $31.35 \%$ & 2108.6281 & $266.34 \%$ \\
\hline Derivative 74 & $\mathrm{C}_{3} \mathrm{H}_{7}$ & $\mathrm{OH}$ & 0.6690 & $149.81 \%$ & 2328.0913 & $19.80 \%$ & 1741.8069 & $202.61 \%$ \\
\hline Derivative 75 & $\mathrm{H}$ & $\mathrm{OH}$ & 0.7210 & $169.23 \%$ & 2404.3628 & $23.72 \%$ & 3881.5037 & $574.34 \%$ \\
\hline Derivative 76 & & $\mathrm{OCH}_{3}$ & 0.7670 & $186.41 \%$ & 2488.8573 & $28.07 \%$ & 7328.2453 & $1173.15 \%$ \\
\hline Derivative 77 & $\mathrm{C}_{2} \mathrm{H}_{5}$ & $\mathrm{OCH}_{3}$ & 0.7420 & $177.07 \%$ & 2624.2185 & $35.03 \%$ & 5296.6344 & $820.19 \%$ \\
\hline Derivative 78 & $\mathrm{SiH}_{3}$ & $\mathrm{OCH}_{3}$ & 0.7560 & $182.30 \%$ & 2529.2980 & $30.15 \%$ & 7533.5556 & $1208.82 \%$ \\
\hline Derivative 79 & $\mathrm{C}_{5} \mathrm{H}_{11}$ & $\mathrm{OCH}_{3}$ & 0.7560 & $182.30 \%$ & 2477.4221 & $27.48 \%$ & 1496.2357 & $159.94 \%$ \\
\hline Derivative 80 & $\mathrm{C}_{3} \mathrm{H}_{7}$ & $\mathrm{CN}$ & 0.7550 & $181.93 \%$ & 2618.1830 & $34.72 \%$ & 6095.3690 & $958.96 \%$ \\
\hline Derivative 81 & $\mathrm{SiH}_{3}$ & $\mathrm{NO}$ & 0.7560 & $182.30 \%$ & 2275.0974 & $17.07 \%$ & 3169.5675 & $450.65 \%$ \\
\hline Derivative 82 & & $\mathrm{NO}_{2}$ & 0.7530 & $181.18 \%$ & 2642.4088 & $35.97 \%$ & 5035.0061 & $774.74 \%$ \\
\hline Derivative 83 & $\mathrm{C}_{2} \mathrm{H}_{5}$ & $\mathrm{NO}_{2}$ & 0.7590 & $183.42 \%$ & 2466.0393 & $26.89 \%$ & 5223.9619 & $807.57 \%$ \\
\hline Derivative 84 & $\mathrm{SiH}_{3}$ & $\mathrm{NO}_{2}$ & 0.7680 & $186.78 \%$ & 2387.8113 & $22.87 \%$ & 7177.9429 & $1147.04 \%$ \\
\hline Derivative 85 & $\mathrm{C}_{3} \mathrm{H}_{7}$ & $\mathrm{NO}_{2}$ & 0.7530 & $181.18 \%$ & 2506.1093 & $28.96 \%$ & 5105.0500 & $786.91 \%$ \\
\hline Derivative 86 & $\mathrm{C}_{4} \mathrm{H}_{9}$ & $\mathrm{NO}_{2}$ & 0.7540 & $181.55 \%$ & 2588.2129 & $33.18 \%$ & 5495.4087 & $854.73 \%$ \\
\hline Derivative 87 & & $\mathrm{CHO}$ & 0.7850 & $193.13 \%$ & 2488.8573 & $28.07 \%$ & 1741.8069 & $202.61 \%$ \\
\hline
\end{tabular}




\subsubsection{The Enhancement of CI, IRI, and UVI of QA Derivatives'}

The Quantitative Mechanism Analysis of the Spectral Enhancement of QA Derivatives Based on the Contour Map

The contour map is used as the basis for obtaining accurate modification information in the 3D-QSAR model. Its spatial distribution and the size of each colored region are closely related to the activity of the designed derivative molecule. Therefore, this paper used marbofloxacin's position 2 as an example to compare the combined effect model of the infrared and ultraviolet spectra with the contour map of the single-effect model. A qualitative mechanism analysis of the spectral enhancement of QA derivatives was conducted in order to reveal the effect of the modified information presented in the contour map on the degree of spectral enhancement of the derivative molecule (Figure 3).
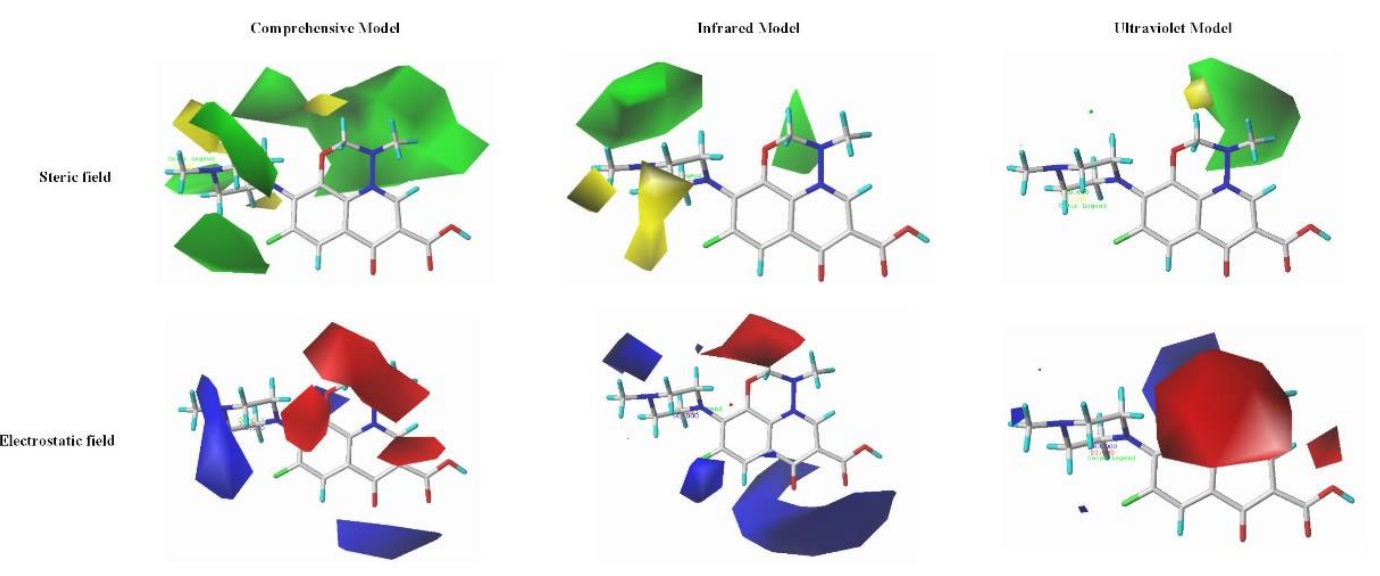

Figure 3. The contour maps of combined effect model and single effect model of infrared and ultraviolet spectra of marbofloxacin.

According to the contour map of the steric field in the comprehensive effect model, the substituent at position 2 is surrounded by a green region, however, the other positions are also surrounded by green regions. Therefore, it can be considered that the steric field is not significant to the contribution of the 2-position substituent. In the infrared-effect model, there is no colored area near the 2-position substituent, thus, the steric field can be considered to have no contribution to the 2-position substituent in the model. In the ultraviolet-effect model, the green region is near the 2-position substituent, and it is the only green region distribution in the contour map. Therefore, the steric field is considered to have the most significant contribution to the 2-position substitution in the model. According to this, it can be qualitatively considered that the order of the contribution rate of the steric field to the modified position is UVI > CI > IRI.

According to the contour map of the steric field, the red area is distributed near the 2-position substituent; however, because the other positions are also close to red areas, the electrostatic field can be considered not significant to the contribution of the 2-position substituent. In the infrared-effect model, there is no colored area near the 2-position substituent, thus, the electrostatic field can be considered to have no contribution to the 2-position substituent in the model; in the ultraviolet-effect model, the red region is near the 2-position substituent, and it is the only red region distribution in the contour map. Therefore, the electrostatic field is considered to have the most significant contribution to the 2-position substitution in the ultraviolet-effect model. According to this, it can be qualitatively considered that the order of the contribution rate of the electrostatic field to the modified position is the UV single effect model $>$ combined effect model $>$ infrared single effect model.

In summary, according to the modified information provided by the contour map, it can be seen that the order of the contribution rate of the steric and electrostatic fields in the three groups of models are the UV single factor model > combined effect model $>$ infrared single effect model. The results are consistent with spectral enhancement (the average value of the combined effect enhancement 
amplitude is $186.46 \%$, the average value of the infrared spectrum single effect enhancement amplitude is $69.45 \%$, and the ultraviolet spectrum single effect enhancement amplitude is $1398.39 \%$ ). This shows that the spectral enhancement amplitude of QA derivatives has a certain internal relationship with the contribution of steric and electrostatic fields to its modified positions. The larger the contribution rate, the larger the corresponding spectral enhancement amplitude.

The Quantitative Mechanism Analysis of the Spectral Enhancement of QA Derivatives Based on the Modified Positions and the Properties of Substituted Groups

In addition to the distribution of colored regions in the contour map, the spectral enhancement amplitude is also affected by the properties of modified positions and the properties of substituted groups. Therefore, the number of modified positions, modified substitutes, and the properties of substituted groups were studied in this paper in order to reveal its intrinsic relationship with the spectral enhancement amplitude (Table 7).

According to the analysis of the data in Table 7, it was found that among the single substitution modification features, seven QA derivatives modified at the 1-position, such as Derivative 1, have an average enhancement range of the CI of $72.06 \%$. The effect enhancement range is $60.02 \%$, and the UV spectrum single effect enhancement range is $339.31 \%$. Derivative 7 and the other 10 QA derivatives modified at the 2-position substituent have an average enhancement range of $113.08 \%$. The single-effect enhancement of the infrared spectrum is $50.80 \%$, and the single-effect enhancement of the ultraviolet spectrum is $421.09 \%$. In the double-substitution modification feature, 70 QA derivatives, such as Derivative 14, are simultaneously modified at the 1- and 2-positions. The average enhancement of the CI is $208.39 \%$, the IRI is $73.05 \%$, and UVI is $1643.92 \%$. From the results, it can be observed that under each substitution feature, the magnitude of the spectral enhancement amplitude in the three groups of models is still the UV single effect model > composite effect model > infrared single effect model, and the results are similar to the size distribution of the color regions in the contour map consistency.

In the comprehensive effect model, the spectral enhancement of QA derivatives obtained by modification at the 1-position, 2-position, and double substitution at 1- and 2-positions were 72.06\%, $113.08 \%$, and $208.39 \%$, respectively. In the infrared single-effect model, the spectral enhancement of QA derivatives obtained by modification at the 1-position, 2-position, and double substitution at 1- and 2-positions were $60.02 \%, 50.80 \%$, and $73.05 \%$, respectively. In the effect model, the spectral enhancement of the QA derivatives obtained by modification at the 1-position, 2-position, and double substitution at 1- and 2-positions were 339.31\%, 421.09\%, and 1643.92\%, respectively. By comparison, it can be found that, with the exception of the infrared single-effect model, the magnitudes of the spectral enhancement amplitudes in the remaining two models are both double-substitution features $>$ 2-position substituent single-substitution features $>1$-position substituent single-substitution features. In addition, the nature of the modified group selected for the 1-position substituent increased by $2.92 \%$, the 2-position substituent was 61.93\%, and the 1- and 2-position substituents were modified at the same time to $79.43 \%$. The spectral enhancement amplitude has universal consistency, which indicates that the spectral enhancement amplitude of QA derivatives has a certain correlation with the properties of modification sites and groups. As the number of modification sites increases, the nature of the modified molecular groups becomes more prominent, and the spectrum will have a greater magnitude of enhancement. 
Table 7. The modified positions and properties of 87 QAs Derivatives.

\begin{tabular}{|c|c|c|c|c|c|c|c|c|c|}
\hline \multirow{2}{*}{$\begin{array}{c}\text { Molecular } \\
\text { Substitution Type }\end{array}$} & \multirow[b]{2}{*}{ QA Derivatives } & \multirow[b]{2}{*}{$\begin{array}{l}\text { 1-Position } \\
\text { Positive }\end{array}$} & \multirow[b]{2}{*}{$\begin{array}{l}\text { Relative } \\
\text { Deviation }\end{array}$} & \multirow[b]{2}{*}{$\begin{array}{l}\text { 2-Position } \\
\text { Negative }\end{array}$} & \multicolumn{5}{|c|}{ Modified Positions and Properties of Substituted Groups } \\
\hline & & & & & $\begin{array}{c}\text { Relative } \\
\text { Deviation }\end{array}$ & $\begin{array}{c}\text { 2-Position } \\
\text { Bigger Group }\end{array}$ & $\begin{array}{c}\text { Relative } \\
\text { Deviation }\end{array}$ & $\begin{array}{l}\text { 2-Position } \\
\text { Coupling }\end{array}$ & $\begin{array}{l}\text { 1, 2-Position } \\
\text { Coupling }\end{array}$ \\
\hline & Marbofloxacin/Levofloxacin & 2.331 & - & 2.331 & - & 15 & - & - & - \\
\hline \multirow{17}{*}{ Monosubstitution } & Derivative 1 & 2.120 & $9.05 \%$ & - & - & - & - & - & - \\
\hline & Derivative 2 & 2.315 & $0.69 \%$ & - & - & - & - & - & - \\
\hline & Derivative 3 & 2.154 & $7.59 \%$ & - & - & - & - & - & - \\
\hline & Derivative 4 & 2.314 & $0.73 \%$ & - & - & - & - & - & - \\
\hline & Derivative 5 & 2.313 & $0.77 \%$ & - & - & - & - & - & - \\
\hline & Derivative 6 & 2.312 & $0.82 \%$ & - & - & - & - & - & - \\
\hline & Derivative 71 & 2.313 & $0.77 \%$ & - & - & - & - & - & - \\
\hline & Derivative 7 & - & - & 2.644 & $13.43 \%$ & 33 & $120.00 \%$ & $66.71 \%$ & - \\
\hline & Derivative 8 & - & - & 2.358 & $1.16 \%$ & 27 & $80.00 \%$ & $40.58 \%$ & - \\
\hline & Derivative 9 & - & - & 2.530 & $8.54 \%$ & 25 & $66.67 \%$ & $37.60 \%$ & - \\
\hline & Derivative 10 & - & - & 2.491 & $6.86 \%$ & 31 & $106.67 \%$ & $56.77 \%$ & - \\
\hline & Derivative 11 & - & - & 2.437 & $4.55 \%$ & 16 & $6.67 \%$ & $5.61 \%$ & - \\
\hline & Derivative 12 & - & - & 2.920 & $25.27 \%$ & 30 & $100.00 \%$ & $62.63 \%$ & - \\
\hline & Derivative 13 & - & - & 3.104 & $33.16 \%$ & 46 & $206.67 \%$ & $119.91 \%$ & - \\
\hline & Derivative 76 & - & - & 2.460 & $5.53 \%$ & 31 & $106.67 \%$ & $56.10 \%$ & - \\
\hline & Derivative 82 & - & - & 3.104 & $33.16 \%$ & 46 & $206.67 \%$ & $119.91 \%$ & - \\
\hline & Derivative 87 & - & - & 2.647 & $13.56 \%$ & 29 & $93.33 \%$ & $53.44 \%$ & - \\
\hline \multirow{14}{*}{ Disubstituted } & Derivative 14 & 2.120 & $9.05 \%$ & 2.644 & $13.43 \%$ & 33 & $120.00 \%$ & $85.90 \%$ & $94.95 \%$ \\
\hline & Derivative 15 & 2.154 & $7.59 \%$ & 2.644 & $13.43 \%$ & 33 & $120.00 \%$ & $85.90 \%$ & $93.49 \%$ \\
\hline & Derivative 16 & 2.314 & $0.73 \%$ & 2.644 & $13.43 \%$ & 33 & $120.00 \%$ & $85.90 \%$ & $86.63 \%$ \\
\hline & Derivative 17 & 2.313 & $0.77 \%$ & 2.644 & $13.43 \%$ & 33 & $120.00 \%$ & $85.90 \%$ & $86.67 \%$ \\
\hline & Derivative 18 & 2.312 & $0.82 \%$ & 2.644 & $13.43 \%$ & 33 & $120.00 \%$ & $85.90 \%$ & $86.71 \%$ \\
\hline & Derivative 19 & 2.200 & $5.62 \%$ & 2.358 & $1.16 \%$ & 27 & $80.00 \%$ & $54.77 \%$ & $60.39 \%$ \\
\hline & Derivative 20 & 2.120 & $9.05 \%$ & 2.358 & $1.16 \%$ & 27 & $80.00 \%$ & $54.77 \%$ & $63.82 \%$ \\
\hline & Derivative 21 & 2.315 & $0.69 \%$ & 2.358 & $1.16 \%$ & 27 & $80.00 \%$ & $54.77 \%$ & $55.46 \%$ \\
\hline & Derivative 22 & 2.154 & $7.59 \%$ & 2.358 & $1.16 \%$ & 27 & $80.00 \%$ & $54.77 \%$ & $62.36 \%$ \\
\hline & Derivative 23 & 2.314 & $0.73 \%$ & 2.358 & $1.16 \%$ & 27 & $80.00 \%$ & $54.77 \%$ & $55.50 \%$ \\
\hline & Derivative 24 & 2.313 & $0.77 \%$ & 2.358 & $1.16 \%$ & 27 & $80.00 \%$ & $54.77 \%$ & $55.54 \%$ \\
\hline & Derivative 25 & 2.312 & $0.82 \%$ & 2.358 & $1.16 \%$ & 27 & $80.00 \%$ & $54.77 \%$ & $55.59 \%$ \\
\hline & Derivative 26 & 2.200 & $5.62 \%$ & 2.530 & $8.54 \%$ & 25 & $66.67 \%$ & $48.07 \%$ & $53.69 \%$ \\
\hline & Derivative 27 & 2.120 & $9.05 \%$ & 2.530 & $8.54 \%$ & 25 & $66.67 \%$ & $48.07 \%$ & $57.12 \%$ \\
\hline
\end{tabular}


Table 7. Cont

\begin{tabular}{|c|c|c|c|c|c|c|c|c|c|}
\hline \multirow{2}{*}{$\begin{array}{c}\text { Molecular } \\
\text { Substitution Type }\end{array}$} & \multirow[b]{2}{*}{ QA Derivatives } & \multirow[b]{2}{*}{$\begin{array}{l}\text { 1-Position } \\
\text { Positive }\end{array}$} & \multirow[b]{2}{*}{$\begin{array}{l}\text { Relative } \\
\text { Deviation }\end{array}$} & \multirow[b]{2}{*}{$\begin{array}{c}\text { 2-Position } \\
\text { Negative }\end{array}$} & \multicolumn{5}{|c|}{ Modified Positions and Properties of Substituted Groups } \\
\hline & & & & & $\begin{array}{c}\text { Relative } \\
\text { Deviation }\end{array}$ & $\begin{array}{c}\text { 2-Position } \\
\text { Bigger Group }\end{array}$ & $\begin{array}{c}\text { Relative } \\
\text { Deviation }\end{array}$ & $\begin{array}{l}\text { 2-Position } \\
\text { Coupling }\end{array}$ & $\begin{array}{l}\text { 1, 2-Position } \\
\text { Coupling }\end{array}$ \\
\hline & Marbofloxacin/Levofloxacin & 2.331 & - & 2.331 & - & 15 & - & - & - \\
\hline & Derivative 28 & 2.315 & $0.69 \%$ & 2.530 & $8.54 \%$ & 25 & $66.67 \%$ & $48.07 \%$ & $48.75 \%$ \\
\hline & Derivative 29 & 2.154 & $7.59 \%$ & 2.530 & $8.54 \%$ & 25 & $66.67 \%$ & $48.07 \%$ & $55.66 \%$ \\
\hline & Derivative 30 & 2.314 & $0.73 \%$ & 2.530 & $8.54 \%$ & 25 & $66.67 \%$ & $48.07 \%$ & $48.79 \%$ \\
\hline & Derivative 31 & 2.313 & $0.77 \%$ & 2.530 & $8.54 \%$ & 25 & $66.67 \%$ & $48.07 \%$ & $48.84 \%$ \\
\hline & Derivative 32 & 2.312 & $0.82 \%$ & 2.530 & $8.54 \%$ & 25 & $66.67 \%$ & $48.07 \%$ & $48.88 \%$ \\
\hline & Derivative 33 & 2.200 & $5.62 \%$ & 2.491 & $6.86 \%$ & 31 & $106.67 \%$ & $74.73 \%$ & $80.35 \%$ \\
\hline & Derivative 34 & 2.120 & $9.05 \%$ & 2.491 & $6.86 \%$ & 31 & $106.67 \%$ & $74.73 \%$ & $83.78 \%$ \\
\hline & Derivative 35 & 2.315 & $0.69 \%$ & 2.491 & $6.86 \%$ & 31 & $106.67 \%$ & $74.73 \%$ & $75.42 \%$ \\
\hline & Derivative 36 & 2.154 & $7.59 \%$ & 2.491 & $6.86 \%$ & 31 & $106.67 \%$ & $74.73 \%$ & $82.32 \%$ \\
\hline & Derivative 37 & 2.314 & $0.73 \%$ & 2.491 & $6.86 \%$ & 31 & $106.67 \%$ & $74.73 \%$ & $75.46 \%$ \\
\hline & Derivative 38 & 2.313 & $0.77 \%$ & 2.491 & $6.86 \%$ & 31 & $106.67 \%$ & $74.73 \%$ & $75.50 \%$ \\
\hline & Derivative 39 & 2.312 & $0.82 \%$ & 2.491 & $6.86 \%$ & 31 & $106.67 \%$ & $74.73 \%$ & $75.54 \%$ \\
\hline & Derivative 40 & 2.200 & $5.62 \%$ & 2.437 & $4.55 \%$ & 16 & $6.67 \%$ & $5.99 \%$ & $11.61 \%$ \\
\hline & Derivative 41 & 2.120 & $9.05 \%$ & 2.437 & $4.55 \%$ & 16 & $6.67 \%$ & $5.99 \%$ & $15.04 \%$ \\
\hline & Derivative 42 & 2.315 & $0.69 \%$ & 2.437 & $4.55 \%$ & 16 & $6.67 \%$ & $5.99 \%$ & $6.67 \%$ \\
\hline & Derivative 43 & 2.154 & $7.59 \%$ & 2.437 & $4.55 \%$ & 16 & $6.67 \%$ & $5.99 \%$ & $13.58 \%$ \\
\hline & Derivative 44 & 2.314 & $0.73 \%$ & 2.437 & $4.55 \%$ & 16 & $6.67 \%$ & $5.99 \%$ & $6.72 \%$ \\
\hline & Derivative 45 & 2.313 & $0.77 \%$ & 2.437 & $4.55 \%$ & 16 & $6.67 \%$ & $5.99 \%$ & $6.76 \%$ \\
\hline & Derivative 46 & 2.312 & $0.82 \%$ & 2.437 & $4.55 \%$ & 16 & $6.67 \%$ & $5.99 \%$ & $6.80 \%$ \\
\hline & Derivative 47 & 2.200 & $5.62 \%$ & 2.920 & $25.27 \%$ & 30 & $100.00 \%$ & $76.09 \%$ & $81.71 \%$ \\
\hline & Derivative 48 & 2.120 & $9.05 \%$ & 2.920 & $25.27 \%$ & 30 & $100.00 \%$ & $76.09 \%$ & $85.14 \%$ \\
\hline & Derivative 49 & 2.315 & $0.69 \%$ & 2.920 & $25.27 \%$ & 30 & $100.00 \%$ & $76.09 \%$ & $76.77 \%$ \\
\hline & Derivative 50 & 2.154 & $7.59 \%$ & 2.920 & $25.27 \%$ & 30 & $100.00 \%$ & $76.09 \%$ & $83.68 \%$ \\
\hline & Derivative 51 & 2.314 & $0.73 \%$ & 2.920 & $25.27 \%$ & 30 & $100.00 \%$ & $76.09 \%$ & $76.82 \%$ \\
\hline & Derivative 52 & 2.313 & $0.77 \%$ & 2.920 & $25.27 \%$ & 30 & $100.00 \%$ & $76.09 \%$ & $76.86 \%$ \\
\hline & Derivative 53 & 2.312 & $0.82 \%$ & 2.920 & $25.27 \%$ & 30 & $100.00 \%$ & $76.09 \%$ & $76.90 \%$ \\
\hline & Derivative 54 & 2.200 & $5.62 \%$ & 3.104 & $33.16 \%$ & 46 & $206.67 \%$ & $151.15 \%$ & $156.76 \%$ \\
\hline & Derivative 55 & 2.120 & $9.05 \%$ & 3.104 & $33.16 \%$ & 46 & $206.67 \%$ & $151.15 \%$ & $160.20 \%$ \\
\hline & Derivative 56 & 2.315 & $0.69 \%$ & 3.104 & $33.16 \%$ & 46 & $206.67 \%$ & $151.15 \%$ & $151.83 \%$ \\
\hline & Derivative 57 & 2.314 & $0.73 \%$ & 3.104 & $33.16 \%$ & 46 & $206.67 \%$ & $151.15 \%$ & $151.87 \%$ \\
\hline & Derivative 58 & 2.313 & $0.77 \%$ & 3.104 & $33.16 \%$ & 46 & $206.67 \%$ & $151.15 \%$ & $151.92 \%$ \\
\hline & Derivative 59 & 2.312 & $0.82 \%$ & 3.104 & $33.16 \%$ & 46 & $206.67 \%$ & $151.15 \%$ & $151.96 \%$ \\
\hline & Derivative 60 & 2.200 & $5.62 \%$ & 2.647 & $13.56 \%$ & 29 & $93.33 \%$ & $67.80 \%$ & $73.42 \%$ \\
\hline
\end{tabular}


Table 7. Cont

\begin{tabular}{|c|c|c|c|c|c|c|c|c|c|}
\hline \multirow{2}{*}{$\begin{array}{c}\text { Molecular } \\
\text { Substitution Type }\end{array}$} & \multirow[b]{2}{*}{ QA Derivatives } & \multirow[b]{2}{*}{$\begin{array}{c}\text { 1-Position } \\
\text { Positive }\end{array}$} & \multirow[b]{2}{*}{$\begin{array}{c}\text { Relative } \\
\text { Deviation }\end{array}$} & \multirow[b]{2}{*}{$\begin{array}{c}\text { 2-Position } \\
\text { Negative }\end{array}$} & \multicolumn{5}{|c|}{ Modified Positions and Properties of Substituted Groups } \\
\hline & & & & & $\begin{array}{c}\text { Relative } \\
\text { Deviation }\end{array}$ & $\begin{array}{c}\text { 2-Position } \\
\text { Bigger Group }\end{array}$ & $\begin{array}{c}\text { Relative } \\
\text { Deviation }\end{array}$ & $\begin{array}{l}\text { 2-Position } \\
\text { Coupling }\end{array}$ & $\begin{array}{l}\text { 1, 2-Position } \\
\text { Coupling }\end{array}$ \\
\hline & Marbofloxacin/Levofloxacin & 2.331 & - & 2.331 & - & 15 & - & - & - \\
\hline & Derivative 61 & 2.120 & $9.05 \%$ & 2.647 & $13.56 \%$ & 29 & $93.33 \%$ & $67.80 \%$ & $76.86 \%$ \\
\hline & Derivative 62 & 2.315 & $0.69 \%$ & 2.647 & $13.56 \%$ & 29 & $93.33 \%$ & $67.80 \%$ & $68.49 \%$ \\
\hline & Derivative 63 & 2.314 & $0.73 \%$ & 2.647 & $13.56 \%$ & 29 & $93.33 \%$ & $67.80 \%$ & $68.53 \%$ \\
\hline & Derivative 64 & 2.313 & $0.77 \%$ & 2.647 & $13.56 \%$ & 29 & $93.33 \%$ & $67.80 \%$ & $68.58 \%$ \\
\hline & Derivative 65 & 2.312 & $0.82 \%$ & 2.647 & $13.56 \%$ & 29 & $93.33 \%$ & $67.80 \%$ & $68.62 \%$ \\
\hline & Derivative 66 & 2.200 & $5.62 \%$ & 2.769 & $18.79 \%$ & 45 & $200.00 \%$ & $142.01 \%$ & $147.63 \%$ \\
\hline & Derivative 67 & 2.120 & $9.05 \%$ & 2.769 & $18.79 \%$ & 45 & $200.00 \%$ & $142.01 \%$ & $151.06 \%$ \\
\hline & Derivative 68 & 2.315 & $0.69 \%$ & 2.769 & $18.79 \%$ & 45 & $200.00 \%$ & $142.01 \%$ & $142.70 \%$ \\
\hline & Derivative 69 & 2.314 & $0.73 \%$ & 2.769 & $18.79 \%$ & 45 & $200.00 \%$ & $142.01 \%$ & $142.74 \%$ \\
\hline & Derivative 70 & 2.313 & $0.77 \%$ & 2.769 & $18.79 \%$ & 45 & $200.00 \%$ & $142.01 \%$ & $142.79 \%$ \\
\hline & Derivative 72 & 2.313 & $0.77 \%$ & 2.358 & $1.16 \%$ & 27 & $80.00 \%$ & $54.77 \%$ & $55.54 \%$ \\
\hline & Derivative 73 & 2.314 & $0.73 \%$ & 2.585 & $10.90 \%$ & 17 & $13.33 \%$ & $12.55 \%$ & $13.28 \%$ \\
\hline & Derivative 74 & 2.314 & $0.73 \%$ & 2.585 & $10.90 \%$ & 17 & $13.33 \%$ & $12.55 \%$ & $13.28 \%$ \\
\hline & Derivative 75 & 2.200 & $5.62 \%$ & 2.585 & $10.90 \%$ & 17 & $13.33 \%$ & $12.55 \%$ & $18.17 \%$ \\
\hline & Derivative 77 & 2.315 & $0.69 \%$ & 2.460 & $5.53 \%$ & 31 & $106.67 \%$ & $74.30 \%$ & $74.99 \%$ \\
\hline & Derivative 78 & 2.120 & $9.05 \%$ & 2.460 & $5.53 \%$ & 31 & $106.67 \%$ & $74.30 \%$ & $83.36 \%$ \\
\hline & Derivative 79 & 2.312 & $0.82 \%$ & 2.460 & $5.53 \%$ & 31 & $106.67 \%$ & $74.30 \%$ & $75.12 \%$ \\
\hline & Derivative 80 & 2.314 & $0.73 \%$ & 2.792 & $19.78 \%$ & 26 & $73.33 \%$ & $56.20 \%$ & $56.92 \%$ \\
\hline & Derivative 81 & 2.120 & $9.05 \%$ & 2.920 & $25.27 \%$ & 30 & $100.00 \%$ & $76.09 \%$ & $85.14 \%$ \\
\hline & Derivative 83 & 2.315 & $0.69 \%$ & 3.104 & $33.16 \%$ & 46 & $206.67 \%$ & $151.15 \%$ & $151.83 \%$ \\
\hline & Derivative 84 & 2.120 & $9.05 \%$ & 3.104 & $33.16 \%$ & 46 & $206.67 \%$ & $151.15 \%$ & $160.20 \%$ \\
\hline & Derivative 85 & 2.314 & $0.73 \%$ & 3.104 & $33.16 \%$ & 46 & $206.67 \%$ & $151.15 \%$ & $151.87 \%$ \\
\hline & Derivative 86 & 2.313 & $0.77 \%$ & 3.104 & $33.16 \%$ & 46 & $206.67 \%$ & $151.15 \%$ & $151.92 \%$ \\
\hline
\end{tabular}




\subsubsection{Molecular Stability Evaluation of QA Derivatives}

The 87 QA derivatives designed based on the CoMFA model are used to characterize the stability of 87 QA derivatives in order to further derivatize QAs.

The positive frequency value of the molecule can directly reflect whether the molecule can stably exist in the environment. When the positive frequency value is greater than zero, it indicates that the molecule can exist stably in the environment; otherwise, it cannot [24,53]. In this paper, DFT was used to calculate the positive frequency values of 87 QAs derivatives to verify their stability (Table 8).

Table 8. The results of positive frequency values of 87 QAs derivatives.

\begin{tabular}{|c|c|c|c|c|c|}
\hline $\begin{array}{c}\text { QA } \\
\text { Derivatives }\end{array}$ & $\begin{array}{c}\text { Positive } \\
\text { Frequency Value }\end{array}$ & $\begin{array}{c}\mathrm{QA} \\
\text { Derivatives }\end{array}$ & $\begin{array}{c}\text { Positive } \\
\text { Frequency Value }\end{array}$ & $\begin{array}{c}\mathrm{QA} \\
\text { Derivatives }\end{array}$ & $\begin{array}{c}\text { Positive } \\
\text { Frequency Value }\end{array}$ \\
\hline Derivative 1 & 20.78 & Derivative 30 & 14.97 & Derivative 59 & 10.15 \\
\hline Derivative 2 & 17.07 & Derivative 31 & 14.85 & Derivative 60 & 28.78 \\
\hline Derivative 3 & 19.93 & Derivative 32 & 12.63 & Derivative 61 & 18.22 \\
\hline Derivative 4 & 15.47 & Derivative 33 & 24.17 & Derivative 62 & 25.68 \\
\hline Derivative 5 & 14.17 & Derivative 34 & 17.19 & Derivative 63 & 23.33 \\
\hline Derivative 6 & 13.15 & Derivative 35 & 18.39 & Derivative 64 & 21.80 \\
\hline Derivative 7 & 25.16 & Derivative 36 & 19.52 & Derivative 65 & 18.79 \\
\hline Derivative 8 & 21.84 & Derivative 37 & 19.74 & Derivative 66 & 28.44 \\
\hline Derivative 9 & 22.60 & Derivative 38 & 14.32 & Derivative 67 & 23.12 \\
\hline Derivative 10 & 20.75 & Derivative 39 & 13.44 & Derivative 68 & 24.75 \\
\hline Derivative 11 & 21.58 & Derivative 40 & 31.02 & Derivative 69 & 22.49 \\
\hline Derivative 12 & 24.54 & Derivative 41 & 20.39 & Derivative 70 & 20.99 \\
\hline Derivative 13 & 22.29 & Derivative 42 & 17.77 & Derivative 71 & 15.37 \\
\hline Derivative 14 & 20.67 & Derivative 43 & 20.83 & Derivative 72 & 11.09 \\
\hline Derivative 15 & 20.88 & Derivative 44 & 20.82 & Derivative 73 & 15.30 \\
\hline Derivative 16 & 18.33 & Derivative 45 & 15.87 & Derivative 74 & 16.74 \\
\hline Derivative 17 & 17.08 & Derivative 46 & 12.92 & Derivative 75 & 28.59 \\
\hline Derivative 18 & 14.97 & Derivative 47 & 24.63 & Derivative 76 & 21.50 \\
\hline Derivative 19 & 21.27 & Derivative 48 & 19.56 & Derivative 77 & 16.28 \\
\hline Derivative 20 & 16.15 & Derivative 49 & 21.39 & Derivative 78 & 19.62 \\
\hline Derivative 21 & 19.96 & Derivative 50 & 14.89 & Derivative 79 & 9.36 \\
\hline Derivative 22 & 18.43 & Derivative 51 & 13.37 & Derivative 80 & 18.66 \\
\hline Derivative 23 & 16.27 & Derivative 52 & 12.78 & Derivative 81 & 16.26 \\
\hline Derivative 24 & 15.53 & Derivative 53 & 7.10 & Derivative 82 & 21.73 \\
\hline Derivative 25 & 14.51 & Derivative 54 & 23.28 & Derivative 83 & 20.00 \\
\hline Derivative 26 & 24.80 & Derivative 55 & 20.02 & Derivative 84 & 21.43 \\
\hline Derivative 27 & 18.49 & Derivative 56 & 17.86 & Derivative 85 & 18.49 \\
\hline Derivative 28 & 21.60 & Derivative 57 & 13.65 & Derivative 86 & 11.53 \\
\hline Derivative 29 & 20.14 & Derivative 58 & 12.72 & Derivative 87 & 23.13 \\
\hline
\end{tabular}

From the above results, the positive frequency values of the 87 QA derivatives are all greater than zero, indicating that all 87 QA derivatives designed in this study can stably exist in the environment.

\subsubsection{Functional and Environmental Friendliness Evaluation of QA derivatives}

Zhao et al. [16,17] selected -lgLOEC (LOEC is the lowest observed effective concentration) to construct a hologram quantitative structure-activity relationship (HQSAR) model of the QAs genetic toxicity. QSAR models were designed independently to predict the genotoxicity, bioaccumulation, and biodegradability of the 87 QA derivatives (Table 9). 
Table 9. Predicted results of genotoxicity, bioaccumulation, and biodegradability of 87 QA derivatives.

\begin{tabular}{|c|c|c|c|c|c|c|}
\hline QA Derivatives & Genotoxicity & $\begin{array}{c}\text { Relative } \\
\text { Deviation }\end{array}$ & Bioaccumulation & $\begin{array}{c}\text { Relative } \\
\text { Deviation }\end{array}$ & Biodegradability & $\begin{array}{c}\text { Relative } \\
\text { Deviation }\end{array}$ \\
\hline Marbofloxacin & 8.4600 & & 1.1840 & & 1.7050 & \\
\hline Derivative 1 & 9.5390 & $12.75 \%$ & 0.9650 & $-18.50 \%$ & 1.7070 & $0.12 \%$ \\
\hline Derivative 2 & 9.8690 & $16.65 \%$ & 1.1630 & $-1.77 \%$ & 1.7250 & $1.17 \%$ \\
\hline Derivative 3 & 9.3760 & $10.83 \%$ & 0.8900 & $-24.83 \%$ & 1.7130 & $0.47 \%$ \\
\hline Derivative 4 & 9.6020 & $13.50 \%$ & 1.1730 & $-0.93 \%$ & 1.7240 & $1.11 \%$ \\
\hline Derivative 5 & 9.5320 & $12.67 \%$ & 1.1740 & $-0.84 \%$ & 1.7250 & $1.17 \%$ \\
\hline Derivative 6 & 9.6380 & $13.92 \%$ & 1.1750 & $-0.76 \%$ & 1.7240 & $1.11 \%$ \\
\hline Derivative 7 & 9.0310 & $6.75 \%$ & 1.3610 & $14.95 \%$ & 1.7190 & $0.82 \%$ \\
\hline Derivative 8 & 8.9180 & $5.41 \%$ & 1.3730 & $15.96 \%$ & 1.7290 & $1.41 \%$ \\
\hline Derivative 9 & 8.5310 & $0.84 \%$ & 1.2810 & $8.19 \%$ & 1.7170 & $0.70 \%$ \\
\hline Derivative 10 & 9.2950 & $9.87 \%$ & 1.5920 & $34.46 \%$ & 1.7030 & $-0.12 \%$ \\
\hline Derivative 11 & 9.8810 & $16.80 \%$ & 1.1110 & $-6.17 \%$ & 1.7130 & $0.47 \%$ \\
\hline Derivative 12 & 8.4810 & $0.25 \%$ & 1.5260 & $28.89 \%$ & 1.6900 & $-0.88 \%$ \\
\hline Derivative 13 & 9.0470 & $6.94 \%$ & 1.2460 & $5.24 \%$ & 1.7350 & $1.76 \%$ \\
\hline Derivative 14 & 9.6010 & $13.49 \%$ & 1.1590 & $-2.11 \%$ & 1.7160 & $0.65 \%$ \\
\hline Derivative 15 & 9.4670 & $11.90 \%$ & 1.0520 & $-11.15 \%$ & 1.7190 & $0.82 \%$ \\
\hline Derivative 16 & 9.8060 & $15.91 \%$ & 0.6090 & $-48.56 \%$ & 1.4940 & $-12.38 \%$ \\
\hline Derivative 17 & 9.7360 & $15.08 \%$ & 0.6080 & $-48.65 \%$ & 1.4940 & $-12.38 \%$ \\
\hline Derivative 18 & 9.8420 & $16.34 \%$ & 0.6060 & $-48.82 \%$ & 1.4940 & $-12.38 \%$ \\
\hline Derivative 19 & 9.2230 & $9.02 \%$ & 0.5660 & $-52.20 \%$ & 1.5050 & $-11.73 \%$ \\
\hline Derivative 20 & 9.4870 & $12.14 \%$ & 0.5650 & $-52.28 \%$ & 1.4990 & $-12.08 \%$ \\
\hline Derivative 21 & 9.9670 & $17.81 \%$ & 0.5720 & $-51.69 \%$ & 1.5000 & $-12.02 \%$ \\
\hline Derivative 22 & 9.4730 & $11.97 \%$ & 0.5430 & $-54.14 \%$ & 1.5040 & $-11.79 \%$ \\
\hline Derivative 23 & 9.7000 & $14.66 \%$ & 0.5760 & $-51.35 \%$ & 1.5070 & $-11.61 \%$ \\
\hline Derivative 24 & 9.6300 & $13.83 \%$ & 0.5760 & $-51.35 \%$ & 1.5060 & $-11.67 \%$ \\
\hline Derivative 25 & 9.7350 & $15.07 \%$ & 0.5760 & $-51.35 \%$ & 1.5100 & $-11.44 \%$ \\
\hline Derivative 26 & 8.8350 & $4.43 \%$ & 0.5470 & $-53.80 \%$ & 1.5260 & $-10.50 \%$ \\
\hline Derivative 27 & 8.9990 & $6.37 \%$ & 0.5450 & $-53.97 \%$ & 1.5230 & $-10.67 \%$ \\
\hline Derivative 28 & 9.5790 & $13.23 \%$ & 0.5550 & $-53.13 \%$ & 1.5290 & $-10.32 \%$ \\
\hline Derivative 29 & 9.0860 & $7.40 \%$ & 0.5230 & $-55.83 \%$ & 1.5220 & $-10.73 \%$ \\
\hline Derivative 30 & 9.3130 & $10.08 \%$ & 0.5910 & $-50.08 \%$ & 1.5270 & $-10.44 \%$ \\
\hline Derivative 31 & 9.2430 & $9.26 \%$ & 0.5950 & $-49.75 \%$ & 1.5290 & $-10.32 \%$ \\
\hline Derivative 32 & 9.3480 & $10.50 \%$ & 0.5970 & $-49.58 \%$ & 1.5300 & $-10.26 \%$ \\
\hline Derivative 33 & 9.6000 & $13.48 \%$ & 0.5350 & $-54.81 \%$ & 1.5060 & $-11.67 \%$ \\
\hline Derivative 34 & 9.7820 & $15.63 \%$ & 0.5330 & $-54.98 \%$ & 1.5010 & $-11.96 \%$ \\
\hline Derivative 35 & 10.3440 & $22.27 \%$ & 0.5450 & $-53.97 \%$ & 1.5030 & $-11.85 \%$ \\
\hline Derivative 36 & 9.8510 & $16.44 \%$ & 0.5120 & $-56.76 \%$ & 1.5020 & $-11.91 \%$ \\
\hline Derivative 37 & 10.0780 & $19.13 \%$ & 0.5440 & $-54.05 \%$ & 1.4980 & $-12.14 \%$ \\
\hline Derivative 38 & 10.0070 & $18.29 \%$ & 0.5440 & $-54.05 \%$ & 1.4990 & $-12.08 \%$ \\
\hline Derivative 39 & 10.1130 & $19.54 \%$ & 0.5440 & $-54.05 \%$ & 1.5010 & $-11.96 \%$ \\
\hline Derivative 40 & 10.1700 & $20.21 \%$ & 0.5020 & $-57.60 \%$ & 1.5130 & $-11.26 \%$ \\
\hline Derivative 41 & 10.1300 & $19.74 \%$ & 0.4950 & $-58.19 \%$ & 1.5120 & $-11.32 \%$ \\
\hline Derivative 42 & 10.9140 & $29.01 \%$ & 0.5150 & $-56.50 \%$ & 1.5090 & $-11.50 \%$ \\
\hline Derivative 43 & 10.4210 & $23.18 \%$ & 0.4680 & $-60.47 \%$ & 1.5150 & $-11.14 \%$ \\
\hline Derivative 44 & 10.6480 & $25.86 \%$ & 0.5600 & $-52.70 \%$ & 1.5180 & $-10.97 \%$ \\
\hline Derivative 45 & 10.5810 & $25.07 \%$ & 1.1810 & $-0.25 \%$ & 1.7350 & $1.76 \%$ \\
\hline Derivative 46 & 10.6870 & $26.32 \%$ & 1.1840 & $0.00 \%$ & 1.7340 & $1.70 \%$ \\
\hline Derivative 47 & 8.7900 & $3.90 \%$ & 1.4680 & $23.99 \%$ & 1.7140 & $0.53 \%$ \\
\hline Derivative 48 & 8.8820 & $4.99 \%$ & 1.5270 & $28.97 \%$ & 1.7120 & $0.41 \%$ \\
\hline Derivative 49 & 9.5340 & $12.70 \%$ & 1.6600 & $40.20 \%$ & 1.7140 & $0.53 \%$ \\
\hline Derivative 50 & 10.2130 & $20.72 \%$ & 1.2030 & $1.60 \%$ & 1.7480 & $2.52 \%$ \\
\hline Derivative 51 & 9.2680 & $9.55 \%$ & 1.6710 & $41.13 \%$ & 1.7140 & $0.53 \%$ \\
\hline Derivative 52 & 9.1970 & $8.71 \%$ & 1.6780 & $41.72 \%$ & 1.7150 & $0.59 \%$ \\
\hline Derivative 53 & 9.3030 & $9.96 \%$ & 1.6730 & $41.30 \%$ & 1.7150 & $0.59 \%$ \\
\hline Derivative 54 & 9.3480 & $10.50 \%$ & 1.2920 & $9.12 \%$ & 1.7150 & $0.59 \%$ \\
\hline Derivative 55 & 9.5060 & $12.36 \%$ & 1.2600 & $6.42 \%$ & 1.7170 & $0.70 \%$ \\
\hline Derivative 56 & 10.0920 & $19.29 \%$ & 1.5080 & $27.36 \%$ & 1.7190 & $0.82 \%$ \\
\hline Derivative 57 & 9.8260 & $16.15 \%$ & 1.5030 & $26.94 \%$ & 1.7150 & $0.59 \%$ \\
\hline Derivative 58 & 9.7550 & $15.31 \%$ & 1.5080 & $27.36 \%$ & 1.7150 & $0.59 \%$ \\
\hline Derivative 59 & 9.8610 & $16.56 \%$ & 1.5100 & $27.53 \%$ & 1.7160 & $0.65 \%$ \\
\hline Derivative 60 & 8.7220 & $3.10 \%$ & 0.8730 & $-26.27 \%$ & 1.6940 & $-0.65 \%$ \\
\hline Derivative 61 & 9.2850 & $9.75 \%$ & 0.9190 & $-22.38 \%$ & 1.6930 & $-0.70 \%$ \\
\hline Derivative 62 & 9.4710 & $11.95 \%$ & 1.1430 & $-3.46 \%$ & 1.7000 & $-0.29 \%$ \\
\hline Derivative 63 & 9.1970 & $8.71 \%$ & 1.1680 & $-1.35 \%$ & 1.7000 & $-0.29 \%$ \\
\hline Derivative 64 & 9.1270 & $7.88 \%$ & 1.1810 & $-0.25 \%$ & 1.7020 & $-0.18 \%$ \\
\hline
\end{tabular}


Table 9. Cont.

\begin{tabular}{|c|c|c|c|c|c|c|}
\hline QA Derivatives & Genotoxicity & $\begin{array}{c}\text { Relative } \\
\text { Deviation }\end{array}$ & Bioaccumulation & $\begin{array}{c}\text { Relative } \\
\text { Deviation }\end{array}$ & Biodegradability & $\begin{array}{c}\text { Relative } \\
\text { Deviation }\end{array}$ \\
\hline Derivative 65 & 9.2330 & $9.14 \%$ & 1.1870 & $0.25 \%$ & 1.7000 & $-0.29 \%$ \\
\hline Derivative 66 & 8.8390 & $4.48 \%$ & 1.2240 & $3.38 \%$ & 1.7380 & $1.94 \%$ \\
\hline Derivative 67 & 9.4460 & $11.65 \%$ & 1.2440 & $5.07 \%$ & 1.7430 & $2.23 \%$ \\
\hline Derivative 68 & 9.5880 & $13.33 \%$ & 1.5060 & $27.20 \%$ & 1.7430 & $2.23 \%$ \\
\hline Derivative 69 & 9.3150 & $10.11 \%$ & 1.5320 & $29.39 \%$ & 1.7400 & $2.05 \%$ \\
\hline Derivative 70 & 9.2440 & $9.27 \%$ & 1.5460 & $30.57 \%$ & 1.7350 & $1.76 \%$ \\
\hline Levofloxacin & 7.9750 & & 1.4590 & & 1.7070 & \\
\hline Derivative 71 & 8.9340 & $12.03 \%$ & 1.5280 & $4.73 \%$ & 1.4730 & $-13.71 \%$ \\
\hline Derivative 72 & 8.7350 & $9.53 \%$ & 1.4300 & $-1.99 \%$ & 1.4750 & $-13.59 \%$ \\
\hline Derivative 73 & 9.0150 & $13.04 \%$ & 1.5230 & $4.39 \%$ & 1.5320 & $-10.25 \%$ \\
\hline Derivative 74 & 9.3700 & $17.49 \%$ & 1.3630 & $-6.58 \%$ & 1.7120 & $0.29 \%$ \\
\hline Derivative 75 & 9.0220 & $13.13 \%$ & 1.4800 & $1.44 \%$ & 1.6800 & $-1.58 \%$ \\
\hline Derivative 76 & 8.4140 & $5.50 \%$ & 1.5220 & $4.32 \%$ & 1.4980 & $-12.24 \%$ \\
\hline Derivative 77 & 9.4620 & $18.65 \%$ & 1.3840 & $-5.14 \%$ & 1.4730 & $-13.71 \%$ \\
\hline Derivative 78 & 8.9870 & $12.69 \%$ & 1.6650 & $14.12 \%$ & 1.4560 & $-14.70 \%$ \\
\hline Derivative 79 & 9.0140 & $13.03 \%$ & 1.2830 & $-12.06 \%$ & 1.5410 & $-9.72 \%$ \\
\hline Derivative 80 & 8.7330 & $9.50 \%$ & 1.5340 & $5.14 \%$ & 1.5350 & $-10.08 \%$ \\
\hline Derivative 81 & 8.5510 & $7.22 \%$ & 1.6340 & $11.99 \%$ & 1.7030 & $-0.23 \%$ \\
\hline Derivative 82 & 8.1340 & $1.99 \%$ & 1.5160 & $3.91 \%$ & 1.4660 & $-14.12 \%$ \\
\hline Derivative 83 & 9.1820 & $15.13 \%$ & 1.6460 & $12.82 \%$ & 1.4190 & $-16.87 \%$ \\
\hline Derivative 84 & 8.4940 & $6.51 \%$ & 1.5230 & $4.39 \%$ & 1.4390 & $-15.70 \%$ \\
\hline Derivative 85 & 8.9160 & $11.80 \%$ & 1.5790 & $8.22 \%$ & 1.4700 & $-13.88 \%$ \\
\hline Derivative 86 & 8.8460 & $10.92 \%$ & 1.5280 & $4.73 \%$ & 1.4610 & $-14.41 \%$ \\
\hline Derivative 87 & 7.9940 & $0.24 \%$ & 1.5970 & $9.46 \%$ & 1.5430 & $-9.61 \%$ \\
\hline
\end{tabular}

Genotoxicity refers to how QAs can selectively inhibit two enzymes that play a role in DNA synthesis in bacteria. Topoisomerase II and IV are two enzymes which interfere with the replication, transcription, repair, and recombination of bacterial DNA. These interferences make it impossible for bacteria to pass down genetic information, which lead to the increase in genotoxicity of QAs, making them conducive to improving the medicinal effect of this class of drugs [54]. According to the prediction results of genotoxicity, compared with marbofloxacin and levofloxacin, the genetic toxicity of 87 QA derivatives increased to varying degrees, and the increase range was $0.24 \%-29.01 \%$.

The n-octanol-water partition coefficient $\left(K_{o w}\right)$ is one of the most important property parameters for studying the environmental behavior of organic matter. This parameter can simulate the distribution behavior of organic matter in lipid and water, and characterize the bioaccumulative ability of organic matter in environmental media. Organic substances with $\log K_{\text {ow }}$ greater than 5.0 are banned worldwide [55]. According to the bioaccumulation prediction results, compared to marbofloxacin and levofloxacin, the bioaccumulation of 49 QA-derived molecules has been reduced to varying degrees, with a decrease of $0.25 \%$ to $60.47 \%$, and the remaining 38 QA-derived molecules increased. The bioaccumulation of the molecule has increased to varying degrees, but its $\log K_{o w}$ value is much lower than 5.0, which is below the banned threshold. Therefore, the bioaccumulation of all $87 \mathrm{QA}$ derivatives are considered to be within the acceptable range.

The biodegradability is expressed by the LibDock Score (LDS) of the oxidoreductase enzyme of Phanerochaete chrysosporium and the QAs in the aerobic process of urban sewage treatment plants. The value of the LDS can represent the biodegradability of QAs [45]. Based on the prediction of biodegradability, it can be seen that compared to marbofloxacin and levofloxacin, the biodegradability of 34 QA derivatives has increased to varying degrees, with an increase of $0.12 \%-2.52 \%$; for the remaining 53 QA derivatives, the biodegradability of biomolecules has decreased, with a decrease range of $0.12 \%-16.87 \%$. Among them, the decline of nine QA derivatives is less than $1 \%$, and their biodegradability can be considered unchanged. A total of 43 QA derivatives with increased or unchanged biodegradability can be selected.

In summary, among the 87 QA derivatives designed in this study, the properties of function (genetic toxicity) and environmentally friendliness (bioaccumulation, biodegradability) of 43 QAs are acceptable. 


\section{Conclusions}

Based on DFT and fuzzy matter-element method, the CI of 24 quinolone antibiotics (QAs) were calculated in this study. A 3D-QSAR model was then constructed by using CI as the dependent variable. A total of $87 \mathrm{QA}$ derivatives with enhanced $\mathrm{CI}$ and single effects were designed. All of the designed QA derivatives can stably exist in the environment, and the functionality and environmental friendliness of 43 QA derivatives are within the acceptable range. Derivative 3 may be considered as an alternative of marbofloxacin with increased genotoxicity $(10.83 \%)$ and biodegradability $(0.47 \%)$, and decreased bioaccumulation (24.83\%). Derivative 74 with the improved genotoxicity $(17.49 \%)$ and biodegradability $(0.29 \%)$, as well as the decreased bioaccumulation $(6.58 \%)$, shows a better performance than levofloxacin. In addition, molecules combined with the modification information provided by the contour map were analyzed to identify why the CI of QA derivatives was enhanced. The research output provides theoretical support for obtaining novel antibiotic drug molecules that are easy to detect and less harmful to the environment and human health.

Supplementary Materials: The following are available online at http://www.mdpi.com/1660-4601/17/9/3239/s1, Figure S1: Relationship between each QA structure and the associated activities (i.e., IRI, UVI and CI) with (a) marbofloxacin and (b) levofloxacin used as the target molecules, Table S1: Molecular structures of designed QA derivatives.

Author Contributions: Conceptualization, X.L., B.Z. and B.C.; methodology, X.L.; software, X.L.; validation, X.L.; formal analysis, X.L.; investigation, X.L.; resources, X.L.; analysis, X.L.; data curation, X.L.; writing-original draft preparation, X.L.; writing-review and editing, X.L., B.Z., W.H., C.C., B.C.; supervision, B.Z. and B.C.; project administration, B.Z.; funding acquisition, B.Z. All authors have read and agreed to the published version of the manuscript.

Funding: This research was funded by Natural Sciences and Engineering Research Council of Canada (NSERC), Canada Research Chair (CRC), and Canadian Foundation of Innovation (CFI).

Conflicts of Interest: The authors declare no conflict of interest.

\section{References}

1. Ma, X. Analysis on Typical Drug Record of Irrational Use of Anti-infective Drugs. China Pharm. 2005, 16, 453-454. (In Chinese)

2. Chen, $X$. The track of clinical medication changes in the past 40 years. New Ed. Pharmacol. 1994, 29, 631-634. (In Chinese)

3. Van Doorslaer, X.; Dewulf, J.; Van Langenhove, H.; Demeestere, K. Fluoroquinolone antibiotics: An emerging class of environmental micropollutants. Sci. Total. Environ. 2014, 500, 250-269. [CrossRef] [PubMed]

4. Zhang, Q.Q. Emission Estimation, Multimedia Fate Modeling and Risk Assessment of Typical Emerging Pollutants at River Basin Scale in China. Ph.D. Thesis, Guangzhou Institute of Geochemistry, Chinese Academy of Sciences, Guangzhou, China, 2015. (In Chinese).

5. Chen, W.P.; Peng, C.W.; Yang, Y.; Wu, Y.M. Distribution Characteristics and Risk Analysis of Antibiotic in the Groundwater in Beijing. Environ. Sci. 2017, 38, 5074-5080. (In Chinese)

6. Serna, R.L.; Jurado, A.; Vázquez-Suñé, E.; Carrera, J.; Petrovic, M.; Barceló, J. Occurrence of 95 pharmaceuticals and transformation products in urban groundwaters underlying the metropolis of Barcelona, Spain. Environ. Pollut. 2013, 174, 305-315. [CrossRef]

7. Fick, J.; Söderström, H.; Lindberg, R.H.; Phan, C.; Tysklind, M.; Larsson, D.G.J. Contamination of surface, ground, and drinking water from pharmaceutical production. Environ. Toxicol. Chem. 2009, 28, 2522. [CrossRef]

8. Bai, Y.; Meng, W.; Xu, J.; Zhang, Y.; Guo, C. Occurrence, distribution and bioaccumulation of antibiotics in the Liao River Basin in China. Environ. Sci. Process. Impacts 2014, 16, 586. [CrossRef]

9. Li, W.; Shi, Y.; Gao, L.; Liu, J.; Cai, Y. Occurrence of antibiotics in water, sediments, aquatic plants, and animals from Baiyangdian Lake in North China. Chemosphere 2012, 89, 1307-1315. [CrossRef]

10. Li, W.; Shi, Y.; Gao, L.; Liu, J.; Cai, Y. Investigation of antibiotics in mollusks from coastal waters in the Bohai Sea of China. Environ. Pollut. 2012, 162, 56-62. [CrossRef] 
11. Zhang, X.; Zhang, H. 3D-QSAR studies on 1,2,4-triazolyl 5-azaspiro [2.4]-heptanes as D 3 R antagonists. Chem. Phys. Lett. 2018, 704, 11-20. [CrossRef]

12. Verma, J.; Khedkar, V.; Coutinho, E. 3D-QSAR in Drug Design - A Review. Curr. Top. Med. Chem. 2010, 10, 95-115. [CrossRef] [PubMed]

13. Wang, X.; Chu, Z.; Yang, J.; Li, Y. Pentachlorophenol molecule design with lower bioconcentration through 3D-QSAR associated with molecule docking. Environ. Sci. Pollut. Res. 2017, 24, 25114-25125. [CrossRef] [PubMed]

14. Tong, J.; Wu, Y.; Bai, M.; Zhan, P. 3D-QSAR and molecular docking studies on HIV protease inhibitors. J. Mol. Struct. 2017, 1129, 17-22. [CrossRef]

15. Gu, W.; Chen, Y.; Zhang, L.; Li, Y. Prediction of octanol-water partition coefficient for polychlorinated naphthalenes through three-dimensional QSAR models. Hum. Ecol. Risk Assess. Int. J. 2016, 23, 1-16. [CrossRef]

16. Zhao, X.; Zhao, Y.; Ren, Z.; Li, Y. Combined QSAR/QSPR and molecular docking study on fluoroquinolones to reduce biological enrichment. Comput. Boil. Chem. 2019, 79, 177-184. [CrossRef]

17. Zhao, X.; Wang, X.; Li, Y. Combined HQSAR method and molecular docking study on genotoxicity mechanism of quinolones with higher genotoxicity. Environ. Sci. Pollut. Res. 2019, 26, 34830-34853. [CrossRef]

18. Petersen, J.C. Thermodynamic study by infrared spectroscopy of the association of 2-quinolone, some carboxylic acids, and the corresponding 2-quinolone-acid mixed dimers. J. Phys. Chem. 1971, 75, 1129-1135. [CrossRef]

19. Efthimiadou, E.K.; Sanakis, Y.; Katsaros, N.; Karaliota, A.; Psomas, G. Transition metal complexes with the quinolone antibacterial agent pipemidic acid: Synthesis, characterization and biological activity. Polyhedron 2007, 26, 1148-1158. [CrossRef]

20. Skyrianou, K.C.; Perdih, F.; Turel, I.; Kessissoglou, D.P.; Psomas, G. Nickel-quinolones interaction. Part 2-Interaction of nickel(II) with the antibacterial drug oxolinic acid. J. Inorg. Biochem. 2010, 104, 161-170. [CrossRef]

21. Zampakou, M.; Akrivou, M.; Andreadou, E.G.; Raptopoulou, C.P.; Psycharis, V.; Pantazaki, A.A.; Psomas, G. Structure, antimicrobial activity, DNA- and albumin-binding of manganese(II) complexes with the quinolone antimicrobial agents oxolinic acid and enrofloxacin. J. Inorg. Biochem. 2013, 121, 88-99. [CrossRef]

22. Bailac, S.; Ballesteros, O.; Jiménez-Lozano, E.; Barron, D.; Nebota, V.S.; Navalón, A.; Vílchez, J.; Barbosa, J. Determination of quinolones in chicken tissues by liquid chromatography with ultraviolet absorbance detection. J. Chromatogr. A 2004, 1029, 145-151. [CrossRef] [PubMed]

23. Hayashi, M.; Lin, S.H.; Raschke, M.B.; Shen, Y.R. A Molecular Theory for Doubly Resonant IR-UV-vis Sum-Frequency Generationt. J. Phys. Chem. A 2002, 106, 2271-2282. [CrossRef]

24. Zeng, X.; Qu, R.; Feng, M.; Chen, J.; Wang, L.; Wang, Z. Photodegradation of Polyfluorinated Dibenzo-p-Dioxins in Organic Solvents: Experimental and Theoretical Studies. Environ. Sci. Technol. 2016, 50, 8128-8134. [CrossRef] [PubMed]

25. Qiu, Y.; Li, Y. A theoretical method for the high-sensitivity fluorescence detection of PAEs through double-substitution modification. Environ. Sci. Pollut. Res. 2018, 25, 34684-34692. [CrossRef] [PubMed]

26. Luze, Y.; Miao, L. 3D-QSAR Model of Polybrominated Biphenyls Tri-effect Modified by Standard Deviation Standardization Method and Its Application in Environmental Friendly Molecular Modification. Chem. J. Chin. Univ. 2019, 40, 2471-2479. (In Chinese)

27. Wang, C.; Wu, A.; Lu, H.; Bao, T.; Liu, X. Predicting rockburst tendency based on fuzzy matter-element model. Int. J. Rock Mech. Min. Sci. 2015, 75, 224-232. [CrossRef]

28. Yang, Q.L.; Guo, Y.B. An entropy fuzzy matter element model for assessment of water resource carrying capacity. Geogr. Geo-Inform. Sci. 2010, 26, 89-92.

29. Liu, N.; Zou, Z. Water quality evaluation based on improved fuzzy matter-element method. J. Environ. Sci. 2012, 24, 1210-1216. [CrossRef]

30. Rai, A.K.; Devlani, N.; Kher, V.H. Spectra and decay rates of bb? meson using Gaussian wave function. In Proceedings of the EPJ Web of Conferences, Dresden, Germany, 25-29 August 2014.

31. Qu, R.; Liu, H.; Feng, M.; Yang, X.; Wang, Z. Investigation on Intramolecular Hydrogen Bond and Some Thermodynamic Properties of Polyhydroxylated Anthraquinones. J. Chem. Eng. Data 2012, 57, 2442-2455. [CrossRef] 
32. Meyer, M.; Steinke, T.; Brandl, M.; Sühnel, J. Density functional study of guanine and uracil quartets and of guanine quartet/metal ion complexes. J. Comput. Chem. 2000, 22, 109-124. [CrossRef]

33. Li, M.; Liu, H.; Zhang, E. Comprehensive Benefit Evaluation of Land Renovation Based on Multiple Indicators. J. Anhui Agric. Sci. 2018, 46, 214-217. (In Chinese)

34. Pan, X.; Liu, H.; Huan, J.; Sui, Y.; Hong, H. Allocation Model of Carbon Emission Permits for the Electric Power Industry with a Combination Subjective and Objective Weighting Approach. Energies 2020, 13, 706. [CrossRef]

35. Chen, Y.; Cai, X.; Jiang, L.; Li, Y. Prediction of octanol-air partition coefficients for polychlorinated biphenyls (PCBs) using 3D-QSAR models. Ecotoxicol. Environ. Saf. 2016, 124, 202-212. [CrossRef] [PubMed]

36. Li, M.; Wei, D.; Zhao, H.; Du, Y. Genotoxicity of quinolones: Substituents contribution and transformation products QSAR evaluation using 2D and 3D models. Chemosphere 2014, 95, 220-226. [CrossRef]

37. Chu, Z.; Li, Y. Designing modified polybrominated diphenyl ether BDE-47, BDE-99, BDE-100, BDE-183, and BDE-209 molecules with decreased estrogenic activities using 3D-QSAR, pharmacophore models coupled with resolution V of the 210-3 fractional factorial design and molecular docking. J. Hazard. Mater. 2019, 364, 151-162. [CrossRef]

38. Zhao, Y.; Li, Y. Design of environmentally friendly neonicotinoid insecticides with bioconcentration tuning and Bi-directional selective toxic effects. J. Clean. Prod. 2019, 221, 113-121. [CrossRef]

39. Qian, S.; Qiao, L.; Xu, W.; Jiang, K.; Wang, Y.; Lin, H. An inner filter effect-based near-infrared probe for the ultrasensitive detection of tetracyclines and quinolones. Talanta 2018, 194, 598-603. [CrossRef]

40. Turiel, E.; Bordin, G.; Rodríguez, A.R. Trace enrichment of (fluoro)quinolone antibiotics in surface waters by solid-phase extraction and their determination by liquid chromatography-ultraviolet detection. J. Chromatogr. A 2003, 1008, 145-155. [CrossRef]

41. Zhao, Y.; Gu, W.; Li, Y. Molecular design of 1,3,5,7-TetraCN derivatives with reduced bioconcentration using 3D-QSAR modeling, full factorial design, and molecular docking. J. Mol. Graph. Model. 2018, 84, 197-214. [CrossRef]

42. Zhao, Y.; Li, Y. Modified neonicotinoid insecticide with bi-directional selective toxicity and drug resistance. Ecotoxicol. Environ. Saf. 2018, 164, 467-473. [CrossRef]

43. Gu, W.; Zhao, Y.; Li, Q.; Li, Y. Environmentally friendly polychlorinated naphthalenes (PCNs) derivatives designed using 3D-QSAR and screened using molecular docking, density functional theory and health-based risk assessment. J. Hazard. Mater. 2019, 363, 316-327. [CrossRef] [PubMed]

44. Gu, W.; Li, Q.; Li, Y. Environment-friendly PCN derivatives design and environmental behavior simulation based on a multi-activity 3D-QSAR model and molecular dynamics. J. Hazard. Mater. 2020, 393, 122339. [CrossRef] [PubMed]

45. Hou, Y.; Zhao, Y.; Li, Q.; Li, Y. Highly biodegradable fluoroquinolone derivatives designed using the 3D-QSAR model and biodegradation pathways analysis. Ecotoxicol. Environ. Saf. 2020, 191, 110186. [CrossRef] [PubMed]

46. Clark, M.; Cramer, R.D.; Van Opdenbosch, N. Validation of the general purpose tripos 5.2 force field. J. Comput. Chem. 1989, 10, 982-1012. [CrossRef]

47. Gasteiger, J.; Marsili, M. Iterative partial equalization of orbital electronegativity-A rapid access to atomic charges. Tetrahedron 1980, 36, 3219-3228. [CrossRef]

48. Leach, A.R. Molecular Modelling: Principles and Applications, 2nd ed.; Pearson Education Ltd.: Essex, UK, 2001; Volume 410, pp. 457-460.

49. Golbraikh, A.; Tropsha, A. Beware of q2! J. Mol. Graph. Model. 2002, 20, 269-276. [CrossRef]

50. Li, X.; Ye, L.; Shi, W.; Liu, H.; Liu, C.; Qian, X.; Zhu, Y.; Yu, H. In silico study on hydroxylated polychlorinated biphenyls as androgen receptor antagonists. Ecotoxicol. Environ. Saf. 2013, 92, 258-264. [CrossRef]

51. Roy, K. On some aspects of validation of predictive quantitative structure-activity relationship models. Expert Opin. Drug Discov. 2007, 2, 1567-1577. [CrossRef]

52. Tropsha, A. Best Practices for QSAR Model Development, Validation, and Exploitation. Mol. Informatics 2010, 29, 476-488. [CrossRef]

53. Jiang, L.; Li, Y. Modification of PBDEs (BDE-15, BDE-47, BDE-85 and BDE-126) biological toxicity, bio-concentration, persistence and atmospheric long-range transport potential based on the pharmacophore modeling assistant with the full factor experimental design. J. Hazard. Mater. 2016, 307, 202-212. [CrossRef] 
54. Aldred, K.J.; Kerns, R.J.; Osheroff, N. Mechanism of Quinolone Action and Resistance. Biochemistry 2014, 53, 1565-1574. [CrossRef] [PubMed]

55. Jackson, S.H.; Cowan-Ellsberry, C.E.; Thomas, G. Use of Quantitative Structural Analysis to Predict Fish Bioconcentration Factors for Pesticides. J. Agric. Food Chem. 2009, 57, 958-967. [CrossRef] [PubMed]

(C) 2020 by the authors. Licensee MDPI, Basel, Switzerland. This article is an open access article distributed under the terms and conditions of the Creative Commons Attribution (CC BY) license (http://creativecommons.org/licenses/by/4.0/). 